\title{
La posición constitucional de las Fuerzas Armadas en España Reflexiones en torno al artículo 8 de la Constitución de 1978
}

Francisco FeRnández Segado

"Artículo 8. - 1. Las Fuerzas Armadas, constituidas por el Ejército de Tierra, la Armada y el Ejército del Aire, tienen como misión garantizar la soberanía e independencia de España, defender su integridad territorial y el ordenamiento constitucional.

2. Una ley orgánica regulará las bases de la organización militar conforme a los principios de la presente Constitución."

\section{El itinerario constituyente del precepto}

El primer atisbo del artículo 8 en el iter constituyente lo encontramos en el artículo 11 de las actas de la ponencia constitucional ${ }^{1}$, artículo relativo a las Fuerzas Armadas, respecto del cual, tras el correspondiente debate, se acordó posponer la discusión de esta materia, sin llegar a prejuzgar su colocación en el Título I o en el que correspondiera ${ }^{2}$. Esta primera toma de contacto con el precepto acontecía en la sesión del $10^{\circ}$ de septiembre de 1977. Dos meses más tarde, en la sesión del 8 de noviembre, la ponencia aprobaba un texto referente a las Fuerzas Armadas que se adjuntaba como artículo 123, precediendo a un artículo relativo a las Fuerzas de Orden Público, dejando pendiente para segunda lectura su colocación ${ }^{3}$. Sin embargo, conviene subrayar que aun cuando la ubicación del precepto seguía estando pendiente de concretar, la alternativa que parecía prosperar en estos momentos del debate de la ponencia no

\footnotetext{
1 Las actas de la ponencia constitucional pueden verse en la Revista de las Cortes Generales, n. 2 , segundo cuatrimestre 1984 , pp. 251 y ss.

2 Ibidem, p. 261.

Ibidem, p. 315.
} 
era la de ubicar el precepto relativo a las Fuerzas Armadas en el título referente al Gobierno, sino situarlo como norma de apertura de un título específicamente dedicado a las «Fuerzas Armadas, de Orden Público y estados de excepción" "4.

Ya en esos momentos la redacción del precepto equivalente al actual artículo 8 era prácticamente idéntica en su apartado primero a la que habría de ser definitiva (con la sola salvedad gramatical del inciso último en el que se hablaba de "proteger el ordenamiento constitucional"), aunque no así en el apartado segundo, al que se daba una redacción mucho más casuística que la que habría de tener en su última versión ${ }^{5}$.

No encontramos en las actas de la ponencia ni el momento en que se acuerda reubicar este artículo en el Título Preliminar, decisión que hay que presuponer vinculada con la de prescindir de un título dedicado a las Fuerzas Armadas y a las de Orden Público, así como a los estados de excepción, ni las razones a que ello responde. Con todo, se puede entresacar una conclusión de los datos que al efecto obran en las actas de la ponencia. Como bien dice LOPEZ RAMON ${ }^{6}$, si bien se obtuvo en la ponencia un cierto acuerdo sobre el contenido del precepto constitucional, no estaba claro el lugar sistemático donde debía incluirse tal norma. Sin embargo, conviene precisar de inmediato algo que no advierte el citado autor: las dudas de la ponencia no oscilaron entre ubicar el artículo bien en el Título Preliminar, bien en el título relativo al Gobierno, sino que, por el contrario, giraron en torno a la opción entre situar la norma referente a las Fuerzas Armadas en el título que constitucionaliza los principios fundamentales de nuestro sistema jurídico-político, o reubicarla en un título "ad hoc» dedicado precisamente a las Fuerzas Armadas, las de Orden Público y los estados de excepción. Por tanto, en las incertidumbres mantenidas al efecto por la ponencia constitucional no parece encontrar cabida en ningún momento la normación de las Fuerzas Armadas en el título que contempla al Gobierno de la nación.

El anteproyecto de Constitución ubicaba finalmente dentro del entonces numerado como Título I («Principios generales»), un artículo

Ibidem, p. 317.

A tenor del apartado segundo del art. 123 del texto-borrador inicialmente redactado por la ponencia constitucional: «Una Ley Orgánica regulará los principios básicos de la Organización Militar dentro de los de la presente Constitución y la composición y funciones de una Junta Superior (de la Defensa), como órgano asesor del Gobierno en los asuntos relativos a la Defensa, así como de una Junta de Jefes de Estado Mayor, como órgano colegiado superior del mando militar de las Fuerzas Armadas."

G Fernando LoPEZ RAMON: La caracterización juridica de Las Fuerzas Armadas, Centro de Estudios Constitucionales, Madrid, 1987, p. 301. 
10, con el que se cerraba el título, sustancialmente coincidente con el actual artículo 8 de la Constitución?

Un total de siete enmiendas se presentaron al texto del artículo $10^{8}$. El punto más controvertido sería el de la composición de las Fuerzas Armadas, que se vería afectado, de una u otra forma, por seis de esas enmiendas. Las misiones de las Fuerzas Armadas serían objeto, directa o indirectamente, de cuatro de las enmiendas. Tres de ellas incidirían sobre el apartado segundo del precepto. Finalmente, sólo dos (las únicas de las que nos ocuparemos ahora): la enmienda n. ${ }^{\circ}$ 64, del diputado $\mathrm{Sr}$. Letamendía Belzunce, del Grupo Parlamentario Mixto, y la n. ${ }^{\circ} 736$, del Sr. Ortí Bordás, de Unión de Centro Democrático, postularían un cambio de ubicación del precepto. Ambas coincidían en propugnar que la normación constitucional de las Fuerzas Armadas debía quedar situada en el título relativo al Gobierno y a la Administración, justificando el Sr. Ortí Bordás tal mutación en la mayor lógica de que el precepto se ubicase en un artículo inmediatamente anterior al referente a las Fuerzas de Orden Público, y no en un título que versa sobre principios generales.

No vamos a entrar en un análisis exhaustivo de los debates constituyentes ${ }^{9}$, ni tan siquiera en este momento de los que tuvieron lugar en relación con la ubicación del precepto ${ }^{10}$. Nos limitaremos a recordar que, obviamente, las enmiendas fueron rechazadas en su totalidad por la ponencia" ${ }^{11}$.

El texto del artículo 8 (nuevo numeral del precepto que nos ocupa, que a la postre sería el definitivo) del informe de la ponencia sería debatido, no por cierto con mucha intensidad, en la sesión de la Comisión de Asuntos Constitucionales y Libertades Públicas del 16 de mayo de $1978^{12}$. Circunscribiéndonos ahora al tema de la ubicación, diremos

La única diferencia entre el texto del art. 10 del anteproyecto y el del actual art. 8 de la Constitución se circunscribe a su apartado segundo. Mientras el texto vigente habla de que la ley orgánica regulará las bases de la organización militar "conforme a los principios de la presente Constitución", el art. 10 del anteproyecto se refería a "dentro de los principios de la presente Constitución", diferencia no sustantiva, circunscrita a la mera construcción gramatical.

8 Enmiendas números 2 (Sr. Carro Martínez, Alianza Popular), 35 (Sr. de la Fuente y de la Fuente, AP), 38 (Sr. Gómez de las Roces, Grupo Parlamentario Mixto), 63 (Sr. Fernández de la Mora, AP), 64 (Sr. Letamendía Belzunce, Grupo Parlamentario Mixto), 463 (Sr. Morodo Leoncio, en nombre del Grupo P. Mixto) y 736 (Sr. Ortí Bordás, Unión de Centro Democráti$\mathrm{co}$ ).

Cfr. al efecto, Manuel Diez Alegria: “La defensa en el proceso constitucional», en Anales de la Real Academia de Ciencias Morales y Politicas, n. 56 (curso 1978-79), pp. 159-182.

i1 Cfr. al respecto Fernando Lopez RAMON: La caracterización juridica..., op. cit., pp. 301 308 .

Boletin Oficial de las Cortes (en adelante BOC), n." 82, 17 de abril de 1978, p. 1527. El debate puede verse en Diario de Sesiones del Congreso de los Diputados (en adelante DSCD), Comisión de Asuntos Constitucionales, n. 67,16 de mayo de 1978, pp. 2375-2380. 
que el Sr. Letamendía, con cuya defensa de su enmienda se inició el debate, argumentaría que "el Ejército es un sector de la Administración, esto es, un agente del Estado, y, como tal, su misión es obedecerlo. Dedicar a la misión del Ejército un artículo del Título Preliminar, que contiene los principios generales de funcionamiento del Estado, equivale a situar al Ejército en un rango distinto, superior al de los demás sectores de la Administración, situación que me parece anormal». A partir de esta reflexión, el Sr. Letamendía entendía que "el encaje idóneo de la función del Ejército está [...] en el Título [...] que trata del Gobierno y de la Administración".

La enmienda -que sería rechazada por 32 votos en contra y ninguno a favor, con dos abstenciones ${ }^{13}$ - suscitaría la réplica del diputado centrista Sr. Herrero de Miñón, quien tras considerar que en el Título Preliminar se comprenden las grandes claves de bóveda del edificio constitucional, entendería por lo mismo conveniente que en dicho título figurara una mención expresa de las Fuerzas Armadas. Y ello por dos razones: por una parte, porque si bien es cierto "que las Fuerzas Armadas son parte de la Administración del Estado y su disposición corresponde al Gobierno, encargado de la defensa y de la administración estatal", "también es claro que las Fuerzas Armadas en la España real de hoy y en el Estado de Derecho del Occidente constituyen una pieza clave para el mantenimiento de ese orden"; y por otra, porque aunque "toda la Administración del Estado de Derecho [...] tiene como última misión el mantenimiento de este ordenamiento constitucional», «a las Fuerzas Armadas se les atribuye la última garantía del ordenamiento jurídico constitucional del Estado. Ello las hace exorbitantes respecto del resto de la Administración Pública». Herrero de Miñón concluiría significando que «las Fuerzas Armadas son Administración Pública, pero son también algo más». Ello incluso explicaría, a juicio del diputado centrista, el por qué la jefatura suprema de esas Fuerzas Armadas se atribuye a «quien es cabeza del Estado y garante de su Constitución, esto es, al Reyn.

El temor ante aquellas posibles interpretaciones que pudieran extraer de la ubicación del precepto dedicado a las Fuerzas Armadas en el Título Preliminar, la errónea y, desde luego, nociva conclusión de una suerte de configuración constitucional de un poder militar dotado de cierta autonomía frente al poder civil, está posiblemente en la base no sólo de las enmiendas que propugnan un cambio de ubicación del precepto, sino también de la enmienda n. ${ }^{\circ} 463$, suscrita por el Sr. Morodo Leoncio en

\footnotetext{
13 La enmienda suscrita por el diputado centrista Sr. Ortí Bordás se entendería decaída al no estar presente en la Comisión, para su defensa, el referido parlamentario.
} 
nombre del Grupo Parlamentario Mixto y defendida en la Comisión por el Sr. Gastón Sanz, quien propugnaría la adición al precepto de las palabras "como agentes del Estado", en coherencia con la determinación constitucional que atribuye al Gobierno la dirección de la Administración militar y de la defensa del Estado ${ }^{14}$.

La cuestión de la que ahora nos venimos ocupando no sería replanteada en el debate ante el Pleno del Congreso ${ }^{15}$, que aprobaba el artículo 8 del texto del dictamen por una abrumadora mayoría de 312 votos a favor frente a dos en contra y dos abstenciones.

En el Senado se presentarían un total de diez enmiendas al texto del precepto que nos interesa. Cinco de ellas: las enmiendas números 172 (del Sr. Gamboa Sánchez-Barcaiztegui), 217 (del Sr. Matutes Juan), 226 (del Sr. Carazo Hernández), 382 (del Sr. Díez Alegría) y 588 (del Sr. de Azcárate Flórez), propugnarían diversas modificaciones respecto de las misiones asignadas a las Fuerzas Armadas, defendiendo a la par la enmienda n. ${ }^{\circ} 172$ una alteración de su composición. La enmienda n. ${ }^{\circ} 135$ (del Sr. Cela y Trulock) postularía unas puntuales modificaciones terminológicas, mientras que la n. 322 (del Sr. Sánchez Agesta) se circunscribiría al texto del apartado segundo. Sólo dos enmiendas: las números 11 (del Sr. Satrústegui Fernández) y 292 (del Sr. Bandrés Molet) se inclinarían por un cambio de ubicación del precepto, que en un caso (enmienda n. ${ }^{\circ} 11$ ) se inclinaba a insertarlo en sus mismos términos tras el artículo que atribuye al Gobierno la dirección de la Administración militar y la defensa del Estado, mientras que en el otro (enmienda n. ${ }^{\circ}$ 292 , del Sr. Bandrés), se ampliaba a una nueva redacción del precepto ${ }^{16}$. La última enmienda (enmienda n. ${ }^{\circ} 448$, del Sr. Xirinacs i Damians) parecía marginal con la cuestión que nos ocupa ${ }^{17}$; sin embargo, puesta

14 Esta enmienda n." 463 sería rechazada por 33 votos en contra y uno a favor, con una abstención.

is Puede verse en DSCD, n. ${ }^{\circ} 104,5$ de julio de 1978, pp. 3880-3887.

16 El Sr. Bandrés proponía la supresión del art. 8 por razones de sistemática, modificación que había de ir acompañada de una nueva redacción del art. 97 (precepto que se ubicaba en el título referente al Gobierno y a la Administración), de conformidad con la cual: «Una ley orgánica determinará las funciones, principios básicos de actuación y estatutos de las Fuerzas Armadas y las Fuerzas de Orden Público."

En su enmienda, el Sr. Xirinacs propugnaba la siguiente redacción para el art. 8: «La Confederación Española renuncia a la guerra como instrumento de su política general y renuncia también a formar parte de cualquier bloque militar internacional." $\mathrm{El}$ influjo que sobre esta enmienda ejercería el art. 6 de la Constitución de la segunda República está fuera de toda duda (a tenor de ese artículo: "España renuncia a la guerra como instrumento de política nacional"). En todo caso, la ausencia de un precepto de naturaleza análoga al del texto republicano puede entenderse suplida, en alguna medida, de un lado, por la proclamación de la voluntad de la nación española (acogida en el Preámbulo de nuestra Carta Magna) de "colaborar en el fortalecimiento de unas relaciones pacíficas y de eficaz cooperación entre todos los pueblos de la Tie- 
en conexión con otra del propio senador (la n..$^{\circ} 522$ ), adquiría plena vinculación con la misma, al propugnar en esta última, entre otras varias cuestiones, el reconocimiento de la misión correspondiente a las Fuerzas Armadas (garantizar la independencia de la Confederación) en un artículo del título relativo al Gobierno y a la Administración.

En la Comisión de Constitución del Senado ${ }^{18}$ se reprodujo el debate que ya tuviera lugar en el seno de la correspondiente comisión de la Cámara Baja. El Sr. Bandrés, en defensa de su enmienda n. ${ }^{\circ} 292$, esgrimiría dos argumentos sustanciales. En primer término, un argumento técnico: las Fuerzas Armadas, «institución que forma parte de la Administración", no han de ocupar en la Constitución un "status" privilegiado en el Título Preliminar, donde se consignan las grandes definiciones y los principios generales del ordenamiento jurídico. En segundo lugar, una razón de corte más político: la aparición de las Fuerzas Armadas en un título en el que no aparecen los poderes del Estado, puede suscitar dudas preocupantes acerca de quién toma la grave decisión de intervención de aquéllas al hallarse en peligro uno de los bienes a cuya salvaguarda se orienta la intervención de las Fuerzas Armadas.

El Sr. Satrústegui, en defensa de su enmienda $n .^{\circ} 11$, de análoga finalidad a la del Sr. Bandrés, esgrimiría la ausencia de precedentes en el Derecho comparado y la lógica de la ubicación de este precepto inmediatamente después de la definición de las facultades del Gobierno, para terminar exponiendo su impresión de que «este artículo (el art. 8) se ha llevado al Título Preliminar creyendo que con esto se halaga a las Fuerzas Armadas». A su vez, el Sr. Villar Arregui, al expresar el apoyo de su Grupo de Progresistas y Socialistas Independientes a la enmienda del senador Sr. Satrústegui, se interrogaba acerca del grado de parentesco jurídico de las Fuerzas Armadas con los sindicatos, las asociaciones de empresarios o los partidos políticos, poniendo de relieve que «el respeto a las instituciones no consiste en conferirles un trato aparentemente privilegiado", sino, bien al contrario, en otorgarles "un tratamiento adecuado a su verdadera naturaleza». Y mal servicio se haría a las Fuerzas

rra", y de otro, por la pertenencia de nuestro país a la Organización de las Naciones Unidas, con la subsiguiente vinculación a los principios de la carta de la ONU, por lo que puede sostenerse que España se encuentra internacionalmente obligada "a no usar las Fuerzas Armadas sino al servicio del interés común" y a observar el párrafo cuarto del art. 2 de la misma carta, que dispone que: "Los miembros de la Organización, en sus relaciones internacionales, se abstendrán de recurrir a la amenaza o al uso de la fuerza contra la integridad territorial o la independencia política de cualquier Estado o en cualquier otra forma incompatible con los propósitos de las Naciones Unidas."

is Diario de Sesiones del Senado (en adelante DSS), Comisión de Constitución, n. ${ }^{\circ} 41,22$ de agosto de 1978, pp. 1707-1717. 
Armadas, a juicio del Sr. Villar Arregui, si se pudiera entender de ellas que son fuerzas sociales, porque, si así fuera, "habríamos llevado a las Fuerzas Armadas al nivel de las bandas armadas, que son las que tienen su origen en la sociedad». Y las Fuerzas Armadas, concluiría el citado senador, no tienen su origen en la sociedad, no se crean espontáneamente en virtud del impulso libre de quien las genera, sino que se inscriben en el área del Estado.

La réplica a las anteriores intervenciones correría a cuenta del senador centrista Sr. González Seara, quien, en lo sustancial, reiteraría los argumentos empleados en el Congreso por el Sr. Herrero de Miñón, subrayando especialmente que aunque las Fuerzas Armadas son parte de la Administración del Estado, "son algo más que mera Administración del Estado y buena y clara prueba de ello es que la Jefatura de las Fuerzas Armadas en la Constitución se le atribuye al Rey».

Las dos enmiendas comentadas serían rechazadas por una gran mayoría de senadores: por 24 votos en contra y una abstención (la del Sr. Bandrés) y por 21 votos contrarios, dos a favor y dos abstenciones (la del Sr. Satrústegui).

En el Pleno de la Alta Cámara ${ }^{19}$ se reproduciría el debate habido en la Comisión de Constitución. El senador Sr. Bandrés, en defensa del cambio de ubicación del precepto, llegaría a aducir que la introducción en el Título Preliminar de la regulación de las Fuerzas Armadas era tanto como "decir que los poderes del Estado son el Poder Legislativo, el Poder Ejecutivo, el Poder Judicial y el Poder de las Fuerzas Armadas, y creo que esto es intolerable en un Estado de Derechom. Junto a ello, el citado senador insistiria en que el precepto dejaba en el aire una grave duda acerca del órgano que había de decidir la intervención de las Fuerzas Armadas a fin de cumplir con alguna de las importantes misiones que la Constitución les atribuye. En análoga dirección, el Sr. Satrústegui argumentaría que si quien manda sobre las Fuerzas Armadas es el Gobierno, el artículo en cuestión "debe de ir en el Capítulo en que se definen cuáles son las facultades del Gobierno, entre las cuales está precisamente la de la defensa». En su contrarréplica, el Sr. González Seara señalaría que "con independencia del viejo planteamiento de Montesquieu (se refiere, como es patente, al principio de la división de poderes), existen unas realidades fundamentales dentro de esa ordenación del poder que entiendo es de buen sentido tratar de asumir en una Constitución".

\footnotetext{
19 Los debates pueden verse en DSS, n. 59 (sesión plenaria n. ${ }^{\circ} 33$ ), 26 de septiembre de 1978, pp. $2941-2948$.
} 
El Pleno del Senado rechazaría por una amplísima mayoría (151 votos en contra, 3 a favor y 29 abstenciones en la enmienda del Sr. Bandrés, y 143 votos opuestos, 33 a favor y 8 abstenciones en el caso de la enmienda del Sr. Satrústegui) ambas enmiendas, aprobando, pues, el texto del artículo 8 en iguales términos que el Congreso, con la única salvedad (modificación introducida por la Comisión de Constitución y más tarde convalidada por la Comisión Mixta Congreso-Senado) de sustituir, en el apartado segundo, la expresión «dentro de los principios de la presente Constitución", por la de "conforme a los principios de la presente Constitución».

Culminaba de esta forma un itinerario marcado por el consenso alcanzado desde el mismo inicio del proceso por las dos grandes formaciones del arco parlamentario.

\section{La singularidad del tratamiento constitucional de las Fuerzas Armadas. Sus posibles explicaciones}

Las Constituciones europeas no suelen contener normas análogas a la del artículo 8. Bien es verdad que algunas puntuales excepciones encontramos frente a esta regla general.

La salvedad quizá más significativa es la de la Constitución Federal austriaca de 1920, cuyo artículo 79 (norma de apertura de una suerte de sección relativa al Ejército federal, que se ubica dentro del apartado dedicado a la Administración, que a su vez se sitúa en la parte tercera de la Constitución, referente al Poder Ejecutivo de la Federación) aborda la regulación de esta materia. Su apartado primero ${ }^{20}$ atribuye al Ejército federal la defensa nacional del país, mientras que el apartado segundo enumera las tareas a las que se destinará el Ejército en la medida en que las autoridades civiles legalmente establecidas lo requieran para ello: protección de las instituciones constitucionales y de su capacidad de funcionamiento, así como de las libertades democráticas de la población; mantenimiento del orden y la seguridad interiores y prestación de ayuda en caso de sucesos y accidentes de magnitud extraordinaria.

Otra excepción la hallamos en el artículo 87 a/ de la Ley Fundamental de Bonn, que se ubica dentro del capítulo referido a la ejecución de las leyes federales y a la Administración federal. Su apartado primero habilita a la Federación para organizar las Fuerzas Armadas para la de-

20 Seguimos el texto de Mariano Daranas: Las Constituciones europeas, Editora Nacional, Madrid, 1979, tomo I. 
fensa, mientras que el siguiente apartado dispone que: "Fuera de la finalidad de defensa, las Fuerzas Armadas sólo podrán ser utilizadas en la medida en que lo permita la presente Ley Fundamental."

La Constitución de Portugal, en su inicial redacción de 1976, dedicaba (dentro de la parte relativa a la organización del poder político) un título a las Fuerzas Armadas. Su artículo 274 las consideraba una institución nacional, mientras que el artículo 273.1 enumeraba sus funciones: garantizar la independencia nacional, la unidad del Estado y la integridad del territorio, añadiendo a ellas en los siguientes apartados del mismo precepto: el aseguramiento de la prosecución de la Revolución de 25 de abril de 1974; la garantía del funcionamiento regular de las instituciones democráticas y del cumplimiento de la Constitución; la garantía de las condiciones que permitan la transición pacífica y pluralista de la sociedad portuguesa a la democracia y al socialismo, y la colaboración en tareas de reconstrucción nacional.

Un precepto de esta naturaleza sólo es explicable, como resulta evidente, en función de las muy peculiares circunstancias de la Revolución de 1974 y del decisivo papel jugado en ella por las Fuerzas Armadas. Sin embargo, la profunda reforma constitucional de 1982 ha conducido a que el título relativo a las Fuerzas Armadas sea sustituido por otro referente a la defensa nacional, en el que se ubica el artículo 275 que contempla a las Fuerzas Armadas, a las que incumbe la defensa militar de la República, que, lógicamente, ha de enmarcarse en la defensa nacional, cuyos objetivos son garantizar, dentro del respeto de las instituciones democráticas, la independencia nacional, la integridad del territorio y la libertad y seguridad de la población frente a cualquier agresión o amenaza externa.

Como puede apreciarse a la vista de lo expuesto, son escasas las normas constitucionales de los países de nuestro entorno que dedican una cierta atención a las Fuerzas Armadas, circunstancia, por cierto, que relativiza muy notablemente el argumento esgrimido por el Sr. Herrero de Miñón en la Comisión de Asuntos Constitucionales del Congreso, en el sentido de buscar una de las apoyaturas del precepto en el Derecho comparado $^{21}$.

21 Es cierto -diría el Sr. Herrero de Miñón- que toda la Administración del Estado de Derecho, todos los órganos del Estado tienen como última misión el mantenimiento de este ordenamiento constitucional. Pero no lo es menos cierto, y ello ha sido algo reconocido por otras Constituciones que en nada pudieron ser sospechosas de proclividad a criterios ajenos al puro Estado de Derecho -y me refiero a la Constitución austriaca, hoy vigente-, que en esas Constituciones a las Fuerzas Armadas se les atribuye esta última garantía del ordenamiento jurídico constitucional del Estado. Ello las hace exorbitantes respecto del resto de la Administración pública (DSCD, n. ${ }^{\circ} 67,16$ de mayo de 1978, p. 2376). 
Esa misma escasez de normas que en este ámbito material nos ofrece el Derecho comparado aún resalta más el indiscutible influjo que sobre el artículo 8 tuvo el artículo 37 de la ley orgánica del Estado de 1967, norma de apertura del Título VI de la misma, título dedicado de modo específico a las Fuerzas Armadas. A tenor del citado precepto: "Las Fuerzas Armadas de la Nación, constituidas por los Ejércitos de Tierra, Mar, Aire y las Fuerzas de Orden Público, garantizan la unidad e independencia de la Patria, la integridad de sus territorios, la seguridad nacional y la defensa del orden institucional."

Basta con la lectura de este artículo para llegar a una primera conclusión: el artículo 37 de la citada ley orgánica del Estado no sólo es el precedente más directo del artículo 8 de nuestra Constitución, sino que puede considerarse incluso como la fuente inmediata de inspiración del constituyente en orden a la ordenación constitucional de las Fuerzas Armadas ${ }^{22}$.

Ahora bien, si original puede considerarse el tratamiento constitucional de las Fuerzas Armadas en el marco del constitucionalismo de nuestro entorno -no así en el de las Constituciones latinoamericanas $^{23}$-, esa singularidad se acentúa aún más, si cabe, si se advierte el lugar de ubicación del precepto: el Título Preliminar. Y es a la vista de todo ello por lo que puede hablarse de la originalidad del tratamiento constitucional de las Fuerzas Armadas en el Código político de 1978. ¿Cuáles son las posibles explicaciones que pueden encontrarse en orden a justificar o explicar esa singularidad?

No creemos que la peculiar ordenación constitucional de los Ejércitos responda a una única motivación. Más bien pensamos que son varias las circunstancias que pueden explicar este singular régimen jurídicoconstitucional. A ellas vamos a intentar referirnos, como también vamos a aludir a alguna otra razón que quizá pudiera entresacarse del debate constituyente $y$-que, a nuestro juicio, en modo alguno puede explicar aquella singularidad.

\footnotetext{
22 En análogo sentido se manifiesta Pablo CASADO BuRBano: Iniciación al Derecho constitucional militar, Editorial Revista de Derecho Privado, Madrid, 1986, p. 26. Y no muy distante es la posición de BALLBE, para quien la intención del legislador constitucional en este extremo ha tenido como punto de referencia, no tanto las Constituciones comparadas, sino el conocimiento de nuestra historia y el articulado de una de las Leyes Fundamentales del régimen precedente del que se pretendía salir. Manuel BaLLBÉ: Orden público y militarismo en la España constitucional (1812-1983), Alianza Universidad, Madrid, 1983, p. 460.

23 Cfr. al efecto, Antonio Porras Nadales: "Ordenamiento de la defensa, poder militar y régimen constitucional en España», en Revista de Estudios Politicos, n. 35 (nueva época), septiembre-octubre 1983, pp. 183 y ss.; en concreto, pp. 221-222 y 225.
} 


\subsection{Las peculiaridades de la transición política}

Los singulares rasgos de la transición política española pueden suministrar un elemento de comprensión de la peculiar ordenación constitucional de las Fuerzas Armadas.

La quiebra del ordenamiento jurídico-político del franquismo a través de la utilización de los cauces previstos por el mismo para su reforma, ilustra significativamente acerca de la originalidad de nuestro proceso de transición de un régimen autoritario a un sistema democrático. El proceso de asunción de un poder constituyente originario viene coartado, a juicio de PORRAS NADALEs ${ }^{24}$, por el hecho de que la iniciativa del proceso es tomada precisamente por los órganos constituidos del anterior ordenamiento.

En este complejo proceso de transición, el papel de las Fuerzas Armadas, bajo la dirección del rey, cuyo mando supremo ejercía, de acuerdo con lo dispuesto por el arrículo 6 de la ley orgánica del Estado, sería realmente notable en orden a su feliz culminación.

Las peculiaridades del proceso explican la existencia en la Constitución de 1978 de lo que VerGOTTINI llamara ${ }^{25}$ "elementi di conservazione del precedente ordinamento", y, entre ellos, «il mantenimento del ruolo di garanzia costituzionale delle Forze Armate ${ }^{26}$.

$Y$ es que, desde luego, el artículo 8 no se sustrae a su antecedente más inmediato: el artículo 37 de la ley orgánica del Estado ${ }^{27}$, del que, como antes dijimos, en buena medida (por supuesto, en mucha mayor medi-

Esta coincidencia con el constitucionalismo latinoamericano es un rasgo también destacado por Juan Fernando Lopez AguILAR: “Defensa, interés nacional y seguridad colectiva» (Acotaciones conceptuales desde el ordenamiento constitucional español), en el colectivo Constitución y Derecho público (Estudios en homenaje a Santiago Varela), Tirant lo Blanch, Valencia, 1995, pp. 241 y ss.; en concreto, p. 249.

24 Antonio Porras Nadales: "Ordenamiento de la defensa...", op. cit., p. 229.

25 Giuseppe DE VERGOTTINI, en el colectivo La Costituzione Spagnola nel trentennale della Costituzione Italiana, Arnaldo Forni Editore, Bologna, 1978, pp. 197 y ss.; en concreto, p. 199.

26 Entre nosotros, Gabriel Elorriaga Fernandez (en "El artículo 8 de la Constitución y la institución nacional de las Fuerzas Armadas", en el colectivo Jornadas de estudio sobre el Titulo Preliminar de la Constitución, vol. IV, Ministerio de Justicia, Madrid, 1988, pp. 2545 y ss.; en concreto, p. 2549) ha recordado cómo el pleno consenso de los sectores políticos constituyentes en torno al art. 8 contrasta con el hecho de ser éste uno de los preceptos que, por su técnica revisionista, es más expresivo del carácter reformista de la transición, frente a otros que podíamos situar más cerca de un carácter rupturista.

27 En igual sentido, Rafael Pérez Escolar: Constitución y Fuerzas Armadas, Asociación Independiente, Madrid, 1981, p. 12. En análogos términos se manifestaría en la Comisión de Constitución del Senado el Sr. Satrústegui Fernández (DSS, n. ${ }^{\circ} 41,22$ de agosto de 1978, p. 1709). 
da que respecto de cualquier otro precedente de Derecho comparado) trae su causa. Pero ello no ha de entenderse, como se sugirió en el debate constituyente, como un halago a las Fuerzas Armadas ${ }^{28}$, ni mucho menos como una muestra de respeto hacia ese "mudo y ciego" que "golpea delante de él allí donde le ponen", como calificara DE VIGNY al Ejército $^{29}$, sino como el reconocimiento de una realidad fáctica. Al decir de SuÁrez Pertierra ${ }^{30}$, la interpretación del artículo 8 es preciso hacerla desde la aplicación de la idea de consenso, que aquí se alza en principio hermenéutico, además de material. La realidad fáctica española, los intereses en juego y las fuerzas en presencia obligaron a ello.

La misma idea está presente larvadamente en el debate constituyente. Y así, por poner dos ejemplos concretos, el Sr. Herrero de Miñón razonaba en la Comisión de Asuntos Constitucionales del Congreso que era claro que «las Fuerzas Armadas en la España real de hoy y en el Estado de Derecho del Occidente constituyen una pieza clave para el mantenimiento de ese orden" (del orden constitucional) ${ }^{31}$. Y el diputado socialista, Sr. Solana Madariaga (Luis), en el Pleno del Congreso, afirmaba: «La realidad es que estamos ante un hecho, y en los temas de guerra, en los temas de la defensa, los hechos priman sobre cualquier otro planteamientor ${ }^{32}$.

En definitiva, parece relativamente claro que el tratamiento constitucional de las Fuerzas Armadas respondió en mayor o menor grado a la constatación de una realidad preexistente que el poder constituyente asume y, por lo mismo, procede a constitucionalizar, sin que ello llegue a suponer, a nuestro juicio y a diferencia de lo que algún otro sector de la doctrina ha apuntado ${ }^{33}$, una verdadera limitación al poder constituyente impuesta por la situación establecida. Y es que, además, no creemos que ésta sea la única, ni tan siquiera la más trascendente, explicación que justifique la razón de ser del artículo 8 .

\footnotetext{
${ }_{28}$ Intervención del senador Sr. Satrústegui Fernández (DSS, n. ${ }^{\circ} 41,22$ de agosto de 1978 , p. 1710 ).

24 Alfredo DE VIGNY: Servidumbre y grandeza militar, Espasa-Calpe (Colección Austral), 3. ${ }^{2}$ ed., Madrid, 1962, p. 18.

31) Gustavo SuÁrez Pertierra: «Regulación jurídico-constitucional de las Fuerzas Armadas", en el colectivo Jornadas de estudio sobre el Titulo Preliminar de la Constitución, op. cit., pp. 2359 y ss.; en concreto, p. 2370.

DSCD, n. ${ }^{\circ} 67,16$ de mayo de 1978 , p. 2376.

DSCD, n. ${ }^{\circ} 104,5$ de julio de 1978, p. 3883.

Antonio PORRAS NADAles: "Ordenamiento de la defensa...", op. cit., p. 224.
} 


\subsection{Las altas misiones de las Fuerzas Armadas}

I. Otra de las posibles explicaciones del encaje del tratamiento constitucional de las Fuerzas Armadas en el Título Preliminar es la relevancia de las misiones atribuidas a aquéllas. Como señalara GuArTA, la trascendencia de las misiones que se asignan a las Fuerzas Armadas justifica la inclusión del precepto que nos ocupa en el Título Preliminar de la Constitución ${ }^{34}$. Pero es que, además, y ello es especialmente significativo, la enumeración de las misiones de las Fuerzas Armadas entraña la vinculación de éstas a aquéllas y, a la par, un límite insalvable frente al poder de dirección política de las Fuerzas Armadas que corresponde al Gobierno, que no puede recurrir a aquéllas más que para el cumplimiento de alguna de las misiones constitucionalmente contempladas y de acuerdo, en cada caso, con el procedimiento constitucional o legalmente establecido.

Las Fuerzas Armadas son el instrumento del poder soberano que integra en la defensa a todo el pueblo, puesto que la soberanía reside en él como totalidad. Como además constituyen una pieza clave para el mantenimiento del orden que para su pacífica convivencia se ha dado el pueblo soberano a través de sus legítimos representantes, parece perfectamente razonable su tratamiento constitucional en el título que expresa, como dice LuCAS Verdú, siguiendo de cerca a SCHMITT ${ }^{35}$, el conjunto de decisiones políticas básicas que configuran la existencia política del pueblo español.

La defensa de la colectividad se convierte de esta forma en la idea que da su razón de ser a las Fuerzas Armadas, entendiendo aquélla -tal y como con excelente criterio dispone el artículo 2 de la ley orgánica 6/ 1980 , de $1 .^{\circ}$ de julio, por la que se regulan los criterios básicos de la defensa nacional y la organización militar-como la disposición, integración y acción coordinada de todas las energías y fuerzas morales y materiales de la nación, ante cualquier forma de agresión, debiendo todos los españoles participar en el logro de tal fin.

Bien es verdad que el progresivo fortalecimiento del Estado ha producido un desplazamiento de lo que en un principio pudieron ser intereses de la sociedad misma, hacia la esfera de lo estatal, de modo tal que

\footnotetext{
34 Aurelio GualTA: “Los derechos fundamentales de los militares", en el colectivo Jornadas de estudio sobre el Título Preliminar..., op. cit., pp. 2561 y ss.; en concreto, p. 2570.

35 Pablo Lucas Verdu: "Título Preliminar", en Oscar Alzaga Villaamil (dir.), Comentarios a las leyes politicas, Editorial Revista de Derecho Privado, tomo I, Madrid, 1983, pp. 19 y ss.; en concreto, p. 20.
} 
aunque la idea de defensa esté fuertemente impresa en la colectividad social, en su articulación prima lo estatal. El Estado, afirma BARCELONA LLOP $^{36}$, para materializar esta idea de la defensa, crea, sostiene y desarrolla unas Fuerzas Armadas, pero ni ello obsta, en contra de lo que el propio autor sostiene, a la caracterización institucional de las mismas, ni es argumento decisivo que impida la configuración constitucional de las Fuerzas Armadas en el Título Preliminar.

Esta enumeración de las altas misiones que se atribuyen a las Fuerzas Armadas ha suscitado otra inquietud que, a nuestro modo de ver, carece de todo sustento. Ya el senador Sr. Bandrés se haría eco de la misma al razonar en la Comisión de Constitución de la Alta Cámara del siguiente modo: «Y yo pregunto, de la simple lectura de este artículo de la Constitución, ¿̨se deduce con claridad quién toma tan grave decisión? ¿Quién toma, en definitiva, la decisión de que las Fuerzas Armadas deben intervenir, porque está en peligro la soberanía o independencia, porque está en peligro la integridad territorial o el ordenamiento constitucional? ${ }^{37}$.

Desde luego, en modo alguno puede estarse de acuerdo con tesis como las de Pérez EsColar ${ }^{38}$, para quien, en cuanto las Fuerzas Armadas forman una pieza de la comunidad española, los problemas de la comunidad les son inherentes, por lo que no deben quedar relegadas a la categoría de instrumento que, en cualquier caso, actúe sin más al dictado del Gobierno, «porque de ser esto válido no se entiende suficientemente el contenido del artículo 8 de la Constitución en su relación sistemática con el artículo $2 \%$.

La Constitución debe ser interpretada sistemáticamente, y ello exige atender al artículo 97, que encomienda a un poder del Estado, emanado de la voluntad del pueblo español, el Poder Ejecutivo, ejercido por el Gobierno, la dirección no sólo de la Administración militar, sino también de la defensa, que, como antes decíamos, da su razón de ser a las Fuerzas Armadas. Es patente, pues, que nuestra «Lex superior» no crea un poder militar autónomo; tal tesis conculcaría frontal y radicalmente los postulados constitucionales. Por lo mismo, no atisbamos a ver la preocupación latente en algunos sectores doctrinales ${ }^{39}$ acerca de la posibilidad de que el Ejército, al amparo del artículo 8, pueda interpretar en

\footnotetext{
36 Javier BARCELONA LLOP: "La organización militar: apuntes jurídico-constitucionales sobre una realidad estatal", en Revista de Administración Pública, n..$^{\circ} 10$, mayo-agosto 1986, pp. 55 y ss.; en concreto, p. 61.

DSS, n. ${ }^{\circ} 41,22$ de agosto de 1978 , p. 1708.

Rafael PÉrEz Escolar: Constitución y Fuerzas Armadas, op. cit., pp. 11-12.

Valga para todos, Javier BARCELONA LLOP: “La organización militar...», op. cit., p. 62.
} 
un momento determinado el alcance y oportunidad de su misión, según los dictados de su propio entendimiento.

II. Una de las características del Estado liberal es la separación entre el poder civil y el poder militar, dando primacía al primero en cuanto poder político. En la teoría de la división de poderes de Montesquieu se puede ver el origen de la doctrina de la subordinación del poder militar al poder civil. Al exaltar la supremacía del Legislativo sobre el Ejecutivo y el Judicial, no siendo los Ejércitos más que un mero brazo del Ejecutivo, se llega a la conclusión de su subordinación al Poder Legislativo, considerado como eminentemente civil ${ }^{40}$.

La separación del poder militar respecto del poder civil y la afirmación orgánica, en sede constitucional, de la superioridad política de este último, se consolidarán en el período de la Revolución francesa ${ }^{41}$.

Es perfectamente conocida la norma de la Constitución de 3 de septiembre de 1791 (art. 12 del Título IV) a cuyo tenor: "La force publique est essentiellement obéissante; nul corps armé ne peut délibérer.» El principio, como diría Dugurr ${ }^{42}$, venía a significar que la fuerza armada debía de ser un instrumento pasivo en manos del Gobierno. Éste no puede cumplir su misión más que si dispone de tal fuerza; ahora bien, «disposer de la force armée, c'est pouvoir s'en servir comme d'une force matérielle inconsciente. Cela exclut la possibilité pour les commandants de la force armée de refuser, sous un prétexte quelconque, d'obtempérer aux ordres du gouvernement".

El referido precepto de la Carta de 1791 se reiterará de una u otra forma en los códigos constitucionales sucesivos. Y así, por recordar tan sólo algunos, el artículo 113 de la Constitución de 24 de junio de 1793 prescribía que: «La force publique employée contre les ennemis du dehors agit sous les ordres du Conseil exécutif», precepto al que seguiría otro del siguiente tenor: "Nul corps armé ne peut délibérer." En la misma dirección, el artículo 275 de la Constitución de 22 de agosto de 1795 reiteraría el texto del artículo antes citado de la Constitución de 1791, mientras que el artículo 274 establecía: «La force armée est instituée pour défendre l'Etat contre les ennemis du dehors, et pour assurer au-dedans le maintien de l'ordre et l'exécution des lois."

41" Luis GarCía ARIAS: "Las Fuerzas Armadas en la ley orgánica del Estado", en Revista de Estudios Politicos, n." 152, marzo-abril 1967, pp. 137 y ss.; en concreto, p. 137.

41 Giuseppe De Vergotrinl: Derecho constitucional comparado, Espasa-Calpe, Madrid, 1983, p. 294.

42 Léon DugurT: Traité de Droit Constitutionnel, tomo IV ("L'Organisation politique de la France"), E. de Boccard, 2." ed., París, 1924, p. 597. 
HAURIOU $^{43}$ se referiría por su parte a cómo la organización del ejército, separada de la del gobierno civil, en unión de la subordinación, de la puesta a disposición de la autoridad civil, de la autoridad militar y de la fuerza armada que manda, habían conseguido el prodigio de que el poder militar permaneciera subordinado al poder civil.

Ya en nuestro tiempo y entre nosotros, un ilustre militar, el general DíEz Alegría, pudo afirmar ${ }^{44}$ que ha constituido siempre un axioma la subordinación del Ejército al poder civil. Para conseguirlo se ha propugnado también el apoliticismo de los miembros de las Fuerzas Armadas.

Si retornamos al análisis de nuestro código constitucional y procedemos, como por otro lado es obligado, a una interpretación sistemática del ordenamiento, podemos advertir que el principio que se sitúa en la misma base del orden constitucional es el de la soberanía del pueblo español, que si bien se residencia en éste como un todo, se expresa a través del pluralismo político que canalizan los partidos, que de esta forma vienen a posibilitar la libre expresión de la voluntad popular. En el marco de la monarquía parlamentaria, forma política de nuestro Estado (art. 1.3 CE), la formación política que cuente con la confianza del Congreso ha de asumir las responsabilidades de gobierno, y en cuanto las Fuerzas Armadas están sujetas al ordenamiento constitucional, cuya defensa política o material última les corresponde, es evidente que han de quedar subordinadas a ese poder civil que simboliza el Gobierno de la nación, en cuanto que éste precisamente encuentra su legitimidad en la voluntad mayoritaria, democráticamente expresada a través de los comicios, del pueblo español, verdadero poder soberano del que las Fuerzas Armadas son un instrumento para la materialización de la defensa nacional. Y ahí encuentra su pleno sentido el artículo 97 de nuestra norma suprema, al atribuir al Gobierno la dirección de la Administración militar y de la defensa del Estado.

En suma, como bien señala LÓPEZ GARRIDO ${ }^{45}$, de una visión de conjunto de la Constitución, como exige toda interpretación jurídica, no cabe deducir una conclusión en el sentido de que los Ejércitos puedan situarse en una posición extravagante a la Constitución, o que pudiera legitimarse una intervención militar decidida autónomamente cuando

Maurice Haurjou: Principios de Derecho público y constitucional traducción de Carlos Ruiz del Castillo, Instituto Editorial Reus, 2." ed., Madrid, 1929, pp. 172-176.

${ }_{44}$ Manuel DIEZ Alegrla: Ejército y sociedad, Alianza Editorial, 2.2 ed., Madrid, 1973, p. 50.

45 Diego López Garrido: "La posición constitucional de las Fuerzas Armadas", en Revista de Administración Pública, n. ${ }^{\circ} 100-102$, vol. II, enero-diciembre 1983, pp. 949 y ss.; en concreto, pp. 951-952. 
las propias Fuerzas Armadas consideren que se dan los supuestos del artículo 8. De esta forma, el citado precepto viene a suponer la inserción de las Fuerzas Armadas en el Estado constitucional de Derecho, no implicando en modo alguno una esfera de poder autónomo para aquéllas.

III. Las argumentaciones que preceden no pueden quedar en modo alguno desvirtuadas por la atribución al rey (art. 62, h/, de la Constitución) del mando supremo de las Fuerzas Armadas.

Una manifestación de la subordinación del Ejército al poder estatal, o lo que es igual, al legítimo poder civil del Estado, se encuentra, a juicio de la doctrina ${ }^{46}$, en el hecho de poner a su cabeza al jefe del Estado, bien entendiéndolo como encarnación de la soberanía en las monarquías tradicionales, bien simplemente encomendando al presidente de la República el mando de las Fuerzas Armadas con una función de garantía constitucional y no meramente simbólica, cual acontece con la Constitución de los Estados Unidos (art. 2, sección segunda, epígrafe I), en donde el presidente, como advierte PRITCHETT ${ }^{47}$, es la cabeza ceremonial, jurídica y administrativa de las Fuerzas Armadas. Sin embargo, en las monarquías parlamentarias en que tal atribución se $\mathrm{da}^{48}$, como sucede en la nuestra, el sentido de ese mando supremo de las Fuerzas Armadas no puede quedar desvinculado del rol constitucional del monarca.

Es cierto que puede detectarse un sector doctrinal que ha intentado contraponer al rey y al Gobierno, sobre la base de que el monarca se halla por encima de los intereses particulares que vendrían a representar los partidos y, por lo mismo, el Gobierno legítimo de la nación, que simbolizaría a una determinada mayoría. La trascendencia e intemporalidad de la defensa nacional, y también de las propias Fuerzas Armadas, que materializan la idea de defensa, exigiría que las mismas se vincularan no a un Gobierno representativo de una mayoría parlamentaria, y, precisamente por ello, temporal, sino al rey, símbolo de la unidad y permanencia de la nación, con cuyos ideales se identifican las Fuerzas Armadas, como dice el artículo 4 de la ley 85/1978, de 18 de diciembre, de Reales Ordenanzas para las Fuerzas Armadas.

46. Francisco JIMÉNEZ Y JIMÉNEZ: Introducción al Derecho penal militar, Civitas, Madrid, 1987, p. 29.

47 C. Herman PritchetT: La Constitución americana, Tipográfica Editora Argentina, Buenos Aires, 1965 , p. 467.

48 Cfr. al efecto, José M. ${ }^{2}$ Lafuente Balle: El rey y las Fuerzas Armadas en La Constitución, Editorial Revista de Derecho Privado, Madrid, 1987, pp. 13-102. 
Este razonamiento puede incluso encontrar un cierto sustento en el debate constituyente, a la vista especialmente de las intervenciones del diputado Sr. Herrero de Miñón, para quien ${ }^{49}$ "las Fuerzas Armadas son Administración pública, pero son también algo más», circunstancia que explicaría "por qué la jefatura suprema de esas Fuerzas Armadas se atribuye a quien es cabeza del Estado y garante de su Constitución, esto es, al Rey". Es conocida la defensa llevada a cabo por el propio HERRERO DE MiNo $N^{50}$ del principio monárquico, en referencia a la figura del rey en las Leyes Fundamentales, principio que, entre otras consecuencias, suponía que al rey le había de corresponder la realidad del mando militar ${ }^{51}$, bien que, en ese momento, el ejercicio del principio monárquico era la vía que podía posibilitar el tránsito de un régimen autoritario a un sistema constitucional y democrático. Bien es cierto que el propio autor ha insistido en sus formulaciones con posterioridad, al sostener ${ }^{52}$ que el mando supremo de las Fuerzas Armadas, que constituye una dirección propiamente política de las mismas, corresponde al rey bajo el refrendo y responsabilidad del Gobierno, pudiendo reducirse tal atribución al mando meramente eminente o simbólico o ampliarse hasta la dirección efectiva de las fuerzas en combate. En todo caso, el mando supremo, como suprema dirección política, se habrá de ejercer mediante actos únicos, esto es, actos que constitucionalmente lo son del rey y cuya génesis supone la concurrencia de la voluntad regia y la voluntad ministerial, expresada en forma de refrendo.

La admisión de esta tesis supondría el reconocimiento de un verdadero poder regio de dirección de las Fuerzas Armadas, incompatible, como razonaremos después, con la naturaleza de la forma política de nuestro Estado. Y de igual forma ha de ser considerada inconciliable con nuestro sistema constitucional la contraposición a la que antes aludíamos entre el rey, en cuanto "elegido de toda la Nación" y el presidente del Gobierno como "tan sólo el jefe de una mayoría". Como bien dice LOPEZ RAMON ${ }^{53}$, con este tipo de expresiones parece querer promoverse una situación de paridad entre el principio monárquico y el principio democrático, en la ignorancia de que nuestro sistema constitucional tan sólo está fundado en el principio democrático, uno de cuyos contenidos

\footnotetext{
49 DSCD, n. 67,16 de mayo de 1978, p. 2376.

51) Miguel Herrero: El principio monárquico (Un estudio sobre la soberanía en las Leyes Fundamentales), Edicusa, Madrid, 1972.

51 Ibidem, p. 118.

s2 Miguel Herrero de MiÑón: "El rey y las Fuerzas Armadas”, en Revista del Departamento de Derecho Politico, n. ${ }^{\circ} 7$, otoño 1980 , pp. 39 y ss.; en concreto, p. 55.

53 Fernando LOPEZ RAMON: La caracterización..., op. cit., 357-358.
} 
es, justamente, el principio mayoritario, no constituyendo el principio monárquico una fuente de legitimación autónoma para el ejercicio del poder $^{54}$.

Un repaso de los pronunciamientos doctrinales en relación con el significado que ha de darse a la atribución constitucional al rey del mando supremo de las Fuerzas Armadas, nos muestra el carácter muy minoritario de quienes han entendido que esta atribución regia va más allá de lo meramente simbólico.

SANCHEZ AGESTA ${ }^{55}$ ve un matiz sutil en la confrontación entre el precepto que atribuye al Gobierno la dirección de la Administración militar y de la defensa del Estado, y aquel otro que encomienda al monarca el mando supremo de los Ejércitos. A su juicio, en aquellos actos que son propios de la competencia del Gobierno, el rey debe estar informado y puede animar o advertir. Por el contrario, en la competencia que se atribuye directamente al rey, aunque no puede ejercerse sin refrendo, parece que puede corresponder al monarca una cierta iniciativa ${ }^{56}$. El Gobierno puede oponerse y ante la insistencia regia, si considera que no debe asumir la responsabilidad de un acto, puede dimitir, lo que es un freno sin duda a esa iniciativa regia moderada así por el refrendo. Esta interpretación ha sido rechazada con toda razón por ALZAGA ${ }^{57}$, quien entiende que tal tesis, llevada hasta sus últimas consecuencias, implicaría el mando efectivo de las Fuerzas Armadas por el rey.

La mayor parte de la doctrina, con unos u otros matices, entiende que este mando supremo atribuido al rey tiene un carácter simbólico o formal. Se trata, dirá ENTRENA ${ }^{58}$, de una función formal y honorífica. Estamos, cree DE EsTEBAN ${ }^{59}$, ante una función simbólica, lo que no im-

${ }_{44}$ Análoga argumentación sostiene Juan Carlos DUQUE VILLANUEVA: «El mando supremo de las Fuerzas Armadas", en el colectivo Jornadas de estudio sobre el Titulo Preliminar de la Constitucion, op. cit., vol. IV, pp. 2529 y ss.; en concreto, pp. 2540-2542.

55 Luis SÁNCHEZ AGESTA: «Significado y poderes de la Corona en el proyecto constitucional', en el colectivo Estudios sobre el proyecto de Constitución, Centro de Estudios Constitucionales, Madrid, 1978, pp. 93 y ss.; en concreto, p. 110.

56 Esta tesis sería reiterada, matizadamente, por el propio autor en El sistema político de la Constitución española de 1978, Editora Nacional, Madrid, 1980, pp. 198-199. Aqquí, SÁNCHEZ AGESTA entiende que puede corresponder al rey una cierta participación, correspondiente a la autoridad de un superior que implica "un mando".

57 Oscar AlzaGa: Comentario sistemático a la Constitución española de 1978, Ediciones del Foro, Madrid, 1978, pp. 414-415.

58 Ramón ENTRENA: "Comentario al artículo 62», en Fernando Garrido Falla (coord.), Comentarios a la Constitución, Editorial Civitas, 2. ${ }^{2}$ ed., Madrid, 1985, pp. 985 y ss.; en concreto, p. 995.

59 Jorge de Esteban y Pedro J. GonzAlez-Trevijano: Curso de Derecho constitucional españoh, III, Universidad Complutense, Madrid, 1994, p. 361. 
pide que, en situaciones de hecho especialmente graves, pueda jugar un papel decisivo el monarca en defensa de la Constitución. LOPEZ GARRIDO $^{60}$ considera por su parte que el mando supremo de las Fuerzas Armadas está incluido en la serie de actos en los que el rey ejerce sólo una función arbitral o moderadora. En análoga dirección, MENENDEZ $\mathrm{REXACH}^{61}$ estima que el mando supremo atribuido al monarca sobre las Fuerzas Armadas no implica la dirección efectiva de las mismas, sino que tiene carácter simbólico, postura compartida por BLANCO VALDES ${ }^{62}$, quien habla del carácter simbólico y representativo de la participación del jefe del Estado tanto en la dirección de la política de defensa a través de su relación con la Junta de Defensa Nacional como de su atribución de mando supremo de los Ejércitos. Y LópEz RAMON ${ }^{63}$, finalmente, bien que sin ánimo exhaustivo, constata cómo la aplicación específica de la teoría general del refrendo a la atribución regia del mando supremo de las Fuerzas Armadas hace que la doctrina mayoritaria espaniola considere que esa atribución es de carácter simbólico, representativo, honorífico, expresión de una autoridad moral.

Introduciendo un ligero matiz en la posición común precedentemente expuesta, MARTÍNEZ LOPEZ-MUNiz ${ }^{64}$ cree que la posición del rey en las Fuerzas Armadas le es asignada con el mismo carácter que las demás competencias constitucionales que le son reconocidas, a través de las cuales se trata de representar la unidad y permanencia del Estado, al tiempo que permiten el ejercicio por su parte de una discreta y operativa función de arbitraje y moderación del regular funcionamiento de las instituciones.

CASADO BURBANO, matizando de igual forma la tesis mayoritaria, entiende ${ }^{65}$ que el significado de ese mando supremo de las Fuerzas Armadas tiene un aspecto representativo o simbólico del que deriva la preeminencia formal sobre toda jerarquía militar, pero tiene también un contenido sustantivo, difícil de plasmar en normas jurídicas concretas,

\footnotetext{
61) Diego LÓpez GarRido: “La posición constitucional de las Fuerzas Armadas", op. cit., p. 968.

Ángel Menéndez ReXACH: La Jefatura del Estado en el Derecho público españoh Instituto Nacional de Administración Pública, Madrid, 1979, p. 409.

62 Roberto L. BLANCO VALDES: La ordenación constitucional de la defensa, Editorial Tecnos, Madrid, 1988, p. 135.

63 Fernando LÓPEZ RAMON: La caracterización jurídica..., op. cit., p. 360.

64 José Luis MARTfNeZ LOPEZ-MuÑIZ: «Fuerzas Armadas y Administración pública», en el colectivo Jornadas de estudio sobre el Titulo Preliminar..., op. cit., vol. IV, pp. 2699 y ss.; en concreto, p. 2705.

65 Pablo Casado Burbano: “Las Fuerzas Armadas en la nueva Constitución española», en Revista Española de Derecho Militar, n. 36 , julio-diciembre 1978, pp. 7 y ss.; en concreto, p. 32.
} 
al que le va bien el calificativo de "suprapolítico" y que se traduce en esa posible actuación arbitral y moderadora, no sujeta a reglas previas, que utiliza como único medio la persuasión y que encuentra su más firme apoyo en la autoridad moral de la persona que la ejerce.

Por nuestra parte, hemos de señalar que la regla general respecto de esta atribución, como la mayoría de la doctrina ha significado, no puede ser diferente de las restantes funciones constitucionalmente atribuidas al rey. En consecuencia, el mando supremo de las Fuerzas Armadas presenta un carácter esencialmente simbólico. Ahora bien, en el ejercicio de esta atribución se acentúan quizá esos derechos regios a que se refería BAGEHOT en 1867 al hablar de la monarquía inglesa. "The sovereign -afirmaría Walter BAGEHOT ${ }^{66}$ - has, under a constitutional monarchy such as ours, three rights: the right to be consulted, the right to encourage, the right to warn. And a king of great sense and sagacity would want no others." Esto es, el rey tiene, respecto del Gobierno que ostenta la dirección efectiva de la Administración militar y de la defensa, correspondiendo, pues, al Ejecutivo la capacidad decisoria en cuanto atañe a una u otra función, el derecho a ser consultado sobre cuanto afecte a las Fuerzas Armadas, el derecho a animar al Ejecutivo en una dirección determinada y, finalmente, el derecho a prevenir sobre los peligros que, a juicio del monarca, pueda entrañar una determinada decisión gubernamental sobre los Ejércitos. Estos derechos, que no se traducen en una competencia determinada, son reconducibles al ámbito de la función arbitral y moderadora que reconoce al monarca el artículo 56 de la Constitución. Están, en suma, más en la línea del ejercicio de la auctoritas que de la potestas.

Al margen de esta línea interpretativa, FERNANDEZ-FONTECHA ${ }^{67}$ ha entendido que el mando supremo, con toda su vaguedad e imprecisión, supone una potestad jurídicamente efectiva y no nominal, aunque ya desarrollada por normas legislativas de rango ordinario. Pero desarrollada en virtud de principios o criterios que no aclaran qué es el mando supremo. El artículo 5 de la ya citada ley orgánica $6 / 1980$, de $1 .^{\circ}$ de julio, prescribe al efecto que: "Corresponden al Rey las funciones que, en materia de defensa nacional, le confieren la Constitución, las Reales Ordenanzas y las demás leyes y, en especial, el mando supremo de las Fuerzas Armadas." Este artículo, nuevamente a juicio de FERNÁNDEZ-

\footnotetext{
6. Walter BAgehot: The English Constitution, Oxford University Press (The World's Classics), Londres, 1974, p. 67.

67 Manuel Fernández-Fontecha Torres y Alfredo Pérez de Armiñán: La monarquía y la Constitución, Editorial Civitas, Madrid, 1987, p. 363.
} 
FONTECHA, nos remite a un problema que se puede plantear en cualquier instante: el problema de la emisión de órdenes regias, naturalmente sujetas al refrendo, con eficacia inmediata sobre la cadena de mando, y eficacia jurídica, no fáctica. El autor centra, pues, el contenido de esta atribución no en el mando político, que el artículo 97 de nuestra norma suprema atribuye inequívocamente al Gobierno, sino en el mando militar, sin precisar qué tipo de órdenes regias pueda dar el rey, con la sujeción al refrendo ministerial.

Ha sido De Oтto quien ha profundizado en esta línea de investigación, partiendo de la tesis de que el mando supremo tiene algún contenido; en concreto, la potestad de dar órdenes propias de los superiores respecto de los inferiores en el seno de la organización militar ${ }^{68}$. Se trataría de una potestad de dar órdenes al margen de la competencia de mando, que el artículo 12.1 de la ley orgánica 6/1980 atribuye a los jefes de Estado Mayor de los tres Ejércitos bajo la autoridad y directa dependencia del ministro de Defensa, quien a su vez ejerce, por delegación del presidente del Gobierno, la facultad de uordenar, coordinar y dirigir la actuación de las Fuerzas Armadas" (artículos 10 y 8.1 de la ley orgánica 6/1980). En tiempo de guerra cabe que el Gobierno nombre al jefe del Estado Mayor de la Defensa, general jefe del mando operativo de las Fuerzas Armadas, ejerciendo, bajo la autoridad del presidente del Gobierno, la conducción de las operaciones militares (art. 11 bis. 3 de la misma ley orgánica 6/1980). En consecuencia, ni en tiempo de paz ni de guerra corresponde al monarca la competencia de mando.

La potestad de dar órdenes, que derivaría del mando, teniéndose aun sin él, no puede ejercerse lícitamente más que de manera complementaria, en el espacio que dejen libres las relaciones de mando, pues es obvio que la superioridad jerárquica no puede utilizarse para invadir competencias ajenas, esto es, en contra del mando de quien lo tenga ${ }^{69}$. De esta forma, el rey, que obviamente no es el jefe de la cadena de mando militar, tendría un supremo poder de dar órdenes que lo convierte en un oficial sin mando situado en la cúspide de la jerarquía militar ${ }^{70}$. El resultado, según DE OTTO ${ }^{71}$, es que el monarca tiene la máxima autoridad militar, pero desprovista por completo de mando, o lo que es igual, tiene la potestad, pero carece de la competencia en que pueda ejercerla lícitamente, con lo que la conclusión final es que la potestad regia de dar

\footnotetext{
68 Ignacio DE OTTO: «El mando supremo de las Fuerzas Armadas», en Revista Española de Derecho Constitucional, n. 23 , mayo-agosto 1988, pp. 11 y ss.; en concreto, p. 37.

Ibidem, p. 39.

Ibidem, p. 40.

Ibidem, p. 41.
} 
órdenes difícilmente puede desplegarse más allá de un terreno puramente simbólico.

Si el rey no puede dar órdenes fuera de las competencias que le sean legalmente reconocidas, y el ordenamiento le aparta de la jefatura de la cadena de mando en cualquier circunstancia, el contenido de esta potestad de mando -que dimana de situarse el monarca en la cúspide jerárquica de una institución fuertemente jerarquizada-se manifiesta tan sólo en lo meramente simbólico, con lo cual la conclusión de DE OTTO no hace, desde nuestro punto de vista, sino corroborar la línea doctrinal mayoritaria a la que hemos venido haciendo referencia. Bien es verdad que en una situación tan extraordinaria como la del 23 de febrero de 1981, una tesis como la inmediatamente antes expuesta cobra una más plena traducción, por cuanto viene a habilitar la utilización por el monarca de esa potestad sin competencia que es la de impartir órdenes militares, cuyo ejercicio resulta ahora legitimado por una doble circunstancia: la imposibilidad física del normal funcionamiento de las instituciones y la existencia de un supuesto de hecho de indisciplina de un sector minoritario de las Fuerzas Armadas. Así las cosas, el rey hace uso de la previsión del inciso final del artículo 38 de las reales ordenanzas, que, taxativamente, prevé: «Ningún jefe tolerará ni disimulará la falta de subordinación.. ${ }^{72}$.

A modo de conclusión de todo lo expuesto, hemos de significar, en coherencia con lo anteriormente dicho, que, a nuestro modo de ver, la atribución al rey del mando supremo de las Fuerzas Armadas no desvirtúa en lo más mínimo la tesis precedentemente referida de la sujeción de las Fuerzas Armadas al legítimo poder civil del Estado.

\subsection{La naturaleza institucional de las Fuerzas Armadas}

La última de las posibles explicaciones que justificarían la inserción en el Título Preliminar del precepto dedicado a las Fuerzas Armadas es la naturaleza institucional de las mismas. A juicio de TrILlo-FigueroA ${ }^{73}$, las Fuerzas Armadas son algo más que un simple denominador común terminológico. Son una unidad institucional. Si esa realidad institucional ejerce materialmente la fuerza legítima o poder coactivo que va implícito en la noción de soberanía, velando por la propia existencia del Estado, no puede concebirse que la Constitución la olvide. Por ello, siempre

\footnotetext{
$72 \quad$ Ibidem, p. 43.

73 Federico Trillo-Figueroa M-Conde: «Las Fuerzas Armadas en la Constitución espanola» (Esbozo de una construcción institucional), en Revista de Estudios Políticos, n. ${ }^{\circ} 12$, noviembre-diciembre 1979 , pp. 105 y ss.; en concreto, pp. 11 y 115.
} 
a juicio del citado autor, la Constitución no sólo acierta al recoger a las Fuerzas Armadas, sino también -y ello es uno de sus mejores logros- al incorporarlas al Título Preliminar, pues éste ha pretendido integrar constitucionalmente las grandes realidades institucionales contemporáneas.

También para ELORRLAGA ${ }^{74}$ resulta evidente que el espíritu constituyente corrobora la idea institucionalista de las Fuerzas Armadas, anteponiéndola a una cierta minusvaloración de la función militar. A su juicio, la voluntad constituyente es muy clara al respecto y legitima la institución nacional de las Fuerzas Armadas con un carácter propio e inconfundible entre las instituciones del Estado ${ }^{75}$.

En dirección similar, bien que subrayando más los aspectos sociológicos, CASADO BURBANO ${ }^{76}$ considera que en cuanto cuerpo social, las Fuerzas Armadas reúnen aquellas notas de objetividad, ordenamiento específico, organización, estabilidad y fin que, entre otras, caracterizan y configuran a toda institución. Son, pues, una institución del Estado que, en último término, persigue los mismos fines que éste. Por su parte, LÓPEZ GARRIDO ${ }^{77}$, a partir del concepto operacional o descriptivo de lo que ha de entenderse por institución, ofrecido por GARCí PELAYO, caracteriza a las Fuerzas Armadas como un ámbito de la estructura estatal que tiende a conformarse como una institución. La Constitución ha asumido esta realidad al mencionarlas expresamente en el Título Preliminar, si bien, a juicio de este autor, ha asumido el aspecto jurídico de la institución, o sea, su sentido unitario en la estructura estatal. En consecuencia, las Fuerzas Armadas son, para LOPEZ GARRIDO, una institución de relevancia constitucional.

No comparten las tesis precedentes un amplio sector de autores, como es el caso de Guarta ${ }^{78}$, para quien la inclusión de las Fuerzas Armadas en el Título Preliminar no implica que aquéllas queden desadministra-

74 Gabriel EloRriaga FernANDEZ: «El artículo 8 de la Constitución y la institución nacional de las Fuerzas Armadas", en el colectivo Jornadas de estudio sobre el Título Preliminar..., vol. IV, op. cit., pp. 2545 y ss.; en concreto, p. 2549.

75 José Luis MARTinez LÓPEZ-MUÑIZ (en “Fuerzas Armadas y Administración pública», op. cit., pp. 2720-2721) sigue también este planteamiento, al señalar que las Fuerzas Armadas son una institución estatal, esto es, una organización instirucional inserta en el Estado, dotada de perfiles organizativos y funcionales propios justificados en su específica misión constitucional.

76 Pablo CaSAdo Burbano: "Las Fuerzas Armadas en la nueva Constitución española», op. cit., p. 9. pp. 957-959.

Diego LOPEZ GARRIDO: «La posición constitucional de las Fuerzas Armadas», op. cit.,

Aurelio GUAITA: "Los derechos fundamentales de los militares", op. cit., p. 2570. Ya este autor (en su Derecho administrativo especial, Librería General, vol. I, Zaragoza, 1965, pp. 61 y ss.), treinta años atrás, defendía la tesis de la Administración militar. 
tivizadas $^{79}$. En la misma dirección, BARCELONA LLOP ${ }^{80}$, tras considerar que el artículo 8 implica el reconocimiento de la trascendencia de la misión estatal de las Fuerzas Armadas, pero en absoluto prejuzga su naturaleza para el Derecho, pues estamos más bien ante un precepto casi testimonial ${ }^{81}$, concluye rechazando la tesis institucional y optando por la de que las Fuerzas Armadas constituyen un sector de la Administración pública ${ }^{82 y 83}$. Y LÓPEZ RAMÓN, tras rechazar la caracterización institucional de las Fuerzas Armadas ${ }^{84}$, se ha inclinado decididamente en favor de la tesis administrativa ${ }^{85}$. A su juicio, la única caracterización posible de las Fuerzas Armadas reside en afirmar su inserción en la Administración del Estado. La expresión "Administración militar» incluye a las Fuerzas Armadas, pues, siempre según LOPEZ RAMÓN, no parece posible reducir el significado de la Administración militar a las estructuras ministeriales de la Administración del Estado, es decir, en la actualidad, al Ministerio de Defensa.

No han faltado algunas posiciones intermedias, como la de SUÁREZ Pertierra, para quien ninguna de las dos categorías de «institución» y "administración" son capaces de abarcar en su conjunto la naturaleza de las Fuerzas Armadas ${ }^{86}$, si bien el citado autor alude con posterioridad a la progresiva administrativización de las Fuerzas Armadas, en lo que parece ser la tesis con la que en mayor grado se siente identificado. DE ESTEBAN, por su parte, considera que la inclusión de las Fuerzas Armadas dentro de la Administración militar no puede desconocer la significación institucional de que disfrutan en nuestro régimen constitucional y la relativa autonomía estructural, funcional y normativa que les reconoce el artículo 8.1 de la Constitución ${ }^{87}$ y 88 .

\footnotetext{
79 Esta tesis es compartida por José M. ${ }^{3}$ LAFUenTE Balle: El rey y las Fuerzas Armadas, op. cit., p. 344.

8) Javier BarCelona Llop: “La organización militar...", op. cit., pp. 58-72.

$81 \quad$ Ibidem, p. 77.

$82 \quad$ Ibidem, p. 71.

83 Para Roberto González Vallejo (en «La Defensa nacional, las Fuerzas Armadas y la Constitución española de 1978", en el colectivo Posición constitucional de las Fuerzas Armadas en Iberoamérica y en España, Tecnos-Universidad Hispanoamericana Santa M. ${ }^{2}$ de la Rábida-Universidad de Sevilla, Madrid, 1992, pp. 123 y ss.; en concreto, p. 131), Administración militar y Fuerzas Armadas son simplemente la misma cosa.

${ }_{84}$ Fernando LOPEZ RAMÓN: La caracterización juridica..., op. cit., pp. 365-369.

85. Ibidem, pp. 376-381.

86 Gustavo SUÁrez Pertierra: "Regulación jurídico-constitucional de las Fuerzas Armadas", op. cit., pp. 2375-2376.

${ }_{87}$ Jorge de Esteban y Pedro J. Gonzalez-Trevijano: Curso de Derecho constitucional espanol, op. cit., III.

${ }_{88}$ Para José Fernández LeRA (en «Constitución y Fuerzas Armadas: una mirada hacia el futurom, en el colectivo Posición constitucional de las Fuerzas Armadas en Iberoamérica y en Espa-
} 
Finalmente, otro sector de la doctrina ${ }^{89}$ considera que la connotación institucionalista del artículo 8 de la Constitución puede ser obviada mediante la noción de poder público. Las Fuerzas Armadas, se sostiene, actúan como poder público. Son, pues, agentes del Estado y no una institución del mismo. Es decir, aunque se admite que el artículo 8 encierra una concepción institucional de los Ejércitos, ésta es rechazada desde otra perspectiva.

Desde nuestro punto de vista, no cabe la menor duda de que las Fuerzas Armadas tienen una naturaleza institucional y esta perspectiva fue tenida en cuenta, indiscutiblemente, por los constituyentes a la hora de su constitucionalización en el Título Preliminar. Es claro que las Fuerzas Armadas son Administración militar, pero son algo más, como se advirtiera en el debate constituyente, de tal forma que ese "algo más" bien puede referirse a esa naturaleza institucional de las Fuerzas Armadas. No digo que ésta fuera la única explicación; es obvio, a estas alturas de mi exposición, que a esta razón se unieron otras, pero, desde luego, es un argumento más que sin duda contó en favor de la ubicación constitucional de las Fuerzas Armadas en el Título Preliminar. Varios argumentos pueden ser esgrimidos, a nuestro modo de ver, para sustentar la tesis insitucional. A ellos pasamos a referirnos.

a) Las Fuerzas Armadas reúnen los rasgos característicos de cualquier institución social. Son, en efecto, un conjunto social perfectamente delimitado frente al exterior, cuyos miembros participan de un sentimiento corporativo que se traduce en una peculiar conciencia de grupo. El que JANOWITZ denominara "military style of life" intensifica la cohesión del grupo y la lealtad personal, coadyuvando asimismo al mantenimiento del espíritu marcial ${ }^{90}$. Y es que, a juicio del propio autor, la profesión militar es más que una ocupación: es un completo estilo de vida. En conexión con tal circunstancia, puede ser considerado como rasgo tradicional de los Ejércitos un cierto aislamiento respecto del resto de la sociedad, que se ha explicado por la propia peculiaridad del «military style of life». "If the military style of life strives to produce an internally cohesive

na $a$, p. cit., pp. 99 y ss.; en concreto, p. 111), el reforzamiento de las Fuerzas Armadas como institución social no excluye su tratamiento como Administración, pero tampoco aquel tratamiento debe ser excluido.

89 Miguel Dominguez-BerRUETA de JuAN y ottos: «El control jurídico constitucional de la transición militarn (Relevancia y conexiones constitucionales del art. 8.1 CE), en el colectivo Jornadas de estudio sobre el Titulo Preliminar de la Constitución, IV, op. cit., pp. 2953 y ss.; en concreto, p. 2962.

9) Morris Janowitz: The Professional Soldier. A social and political portrait, The Free Press Paperback, Macmillan, Londres, 4." impr., 1968, p. 175. 
community -manifiesta JANOWITZ ${ }^{91}$-, at the same time, it thwarts social integration with civilian society."

b) Las Fuerzas Armadas tienen un específico código de valores ${ }^{92}$. En los últimos doscientos años, afirma MARTIN JIMÉNEZ ${ }^{33}$, los Ejércitos han conservado en lo esencial los valores tradicionales que les animan. Este conjunto de valores conecta con un peculiar modo de sentir y pensar, esto es, con lo que ha sido denominado la mentalidad militar. Sería HUNTINGTON quien por vez primera acuñara la expresión "the military mind, ${ }^{94}$. El Título II de las Reales Ordenanzas para las Fuerzas Armadas, aprobadas por la ley $85 / 1978$, de 28 de diciembre, contiene los principios éticos que deben informar, en todo momento, la conducta del militar, sus virtudes fundamentales: la disciplina, el sentimiento del honor, la subordinación, la discreción, el espíritu de unidad... etc. El propio Tribunal Constitucional se ha referido a este peculiar código de valores ${ }^{95}$ al razonar que los bienes jurídicos protegidos por los delitos contra el honor militar "guardan relación directa con la peculiar naturaleza y singulares valores de la organización castrense, dentro de la que destaca la condición o status de militar, como particular manera de ser y actuar en pro de altos fines, que comporta la sujeción a un sistema normativo en que se imponen de forma muy significativa determinados valores [...].».

c) Esta peculiaridad de los miembros de la institución castrense se orienta al logro de una idea objetiva, idea sobre la cual, como señalara HAURIOU $^{96}$, va a reposar la institución, convirtiéndose en la idea-fuerza que atrae a su alrededor simpatías, vocaciones y concursos. Esta idea es la defensa militar de España, razón de ser de los Ejércitos, como dice el artículo 3 de las Reales Ordenanzas para las Fuerzas Armadas.

d) La institución tiene una alta valoración de su propia misión, lo que ha conducido a la misma a una cierta autosuficiencia respecto a la sociedad exterior. Quizá sea significativo al respecto el dicho inglés: «There are three ways to get the things done: the right way, the wrong way and the military way.»

\footnotetext{
9i Ibidem, p. 204.

22 Cfr. al efecto, Francisco FERNÁNDEZ SEGADO: "El perfil diferencial de la escala de valores de la institución militar", en Revista de Estudios Politicos, n. ${ }^{\circ} 51$, mayo-junio 1986, p. 79 y ss.; en especial, pp. 101-113.

9.3 Hilario MARTIN JIMÉNEZ: Los valores morales de las Fuerzas Armadas en las reales ordenanzas de S.M.D. Juan Carlos I, Imprenta Litomaype, La Laguna, 1980, p. 35.

${ }_{94}$ Samuel P. HunTINGTON: The Soldier and the State. The theory and politics of civil-military relations, The Belknap Press of Harvard University Press, Cambridge, Massachusetts, 5.' impr., 1972 , pp. 59 y ss.

95 Auto del Tribunal Constitucional 446/1984, de 11 de julio, fund. jur. 6.

96 Maurice Hauriou: Principios de Derecho público y constitucional, op. cit., p. 85.
} 
e) La institución tiene su propio ordenamiento jurídico, el Derecho militar, que contribuye a darle cohesión y eficacia. Dondequiera que han existido Fuerzas Armadas regulares y organizadas, afirma QUEROL Y DURÁN ${ }^{97}$, han funcionado, más o menos embrionariamente, las leyes y justicia de carácter militar específico, porque siempre ha sido facultad y deber del mando mantener, en las huestes sobre las que se ejerce, la disciplina, a cuyo fin es indispensable el uso rápido y eficaz del poder punitivo ${ }^{98}$. En análoga dirección, CASADO BURBANO ${ }^{99}$ ha constatado que desde tiempos remotos puede apreciarse como un núcleo esencial de bienes y valores protegidos por normas penales que hacen relación directa a la eficacia de las Fuerzas Armadas en el combate.

f) La institución militar requiere, para el eficaz cumplimiento de sus altas misiones, de una específica forma de organización y de un régimen jurídico singular del personal integrado en la institución, como el propio Tribunal Constitucional ha tenido oportunidad de reconocer ${ }^{100}$ y 101. Las Fuerzas Armadas se inspiran todavía en una concepción monolítica que prevé la concentración del poder decisorio en una estructura unitaria ${ }^{102}$. De esta forma, la jerarquía se convierte en el instrumento fundamental de la organización operativa, indispensable para conseguir la unidad de acción, de dirección y de mando. La jerarquía, ha dicho RoJAS CARO, es el hilo conductor de las Fuerzas Armadas como paradigmática estructura de autoridad que condiciona toda la vida del organismo y resplandece en el ámbito de las relaciones interindividuales de los mili-

\footnotetext{
97 Fernando DE QUeRol y DURAN: Principios de Derecho militar español, Editorial Naval, tomo I, Madrid, 1948, p. 31.

98 Bien es verdad que, como señala Vicenzo MANZINI (Diritto Penale Militare, 2.2 ed., Padova, 1932, p. 2, nota 2), todos los códigos militares traen principalmente su origen de las instituciones creadas por la Revolución francesa, a partir del "Code des délits et des peines pour les tropes de la Républiquen, de 11 de noviembre de 1796.

99 Pablo Casado BURBano: «Visión histórica del Derecho penal militar español. Comentario al Capítulo I del Código Penal Militar", en Ramón Blecua y José Luis Rodríguez-Villasante (dirs.), Comentarios al Código Penal Militar, Civitas, Madrid, 1988, pp. 29 y ss.; en concreto, p. 29.

106) STC 107/1986, de 24 de julio, fund. jur. 4.

101 No puede caber duda -ha admitido el Tribunal Constitucional, en su auto 375/1983, de 30 de julio, fund. jur. 2- que, dada la importante misión que a las Fuerzas Armadas asigna el art. 8.1 CE, representa un interés de singular relevancia en el orden constitucional el que las mismas se hallen configuradas de modo que sean idóneas y eficaces para el cumplimiento de sus altos fines. A tal fin, la específica naturaleza de la profesión militar exige en su organización $u n$ indispensable sistema jerárquico manifestado en una especial situación de sujeción enmarcada en la disciplina, que impone una precisa vinculación descendente para conseguir la máxima eficacia y el factor de precisa conexión que obliga a todos por igual.

162 Antonio INTELISANo, en la obra colectiva coordinada por Silvio Rondato, Il nuovo ordinamento disciplinare delle Forze Armate, CEDAM, Padova, 1987, p. 15.
} 
tares en el interior del sistema ${ }^{103}$. Las mismas peculiaridades del Derecho penal y procesal militar resultan genéricamente de esta organización profundamente jerarquizada de las Fuerzas Armadas, como el propio juez de la Constitución ha admitido ${ }^{104 \text { y } 105}$.

g) Finalmente, como acabamos de decir, la pertenencia a la institución comporta, en aras de la eficacia de la misma, un régimen jurídico singular, un "status" particular del personal integrado en aquélla. Como en otro lugar hemos señalado ${ }^{106}$, la especialidad de este régimen tiene como última "ratio" el mantenimiento de los que pueden ser considerados como los tres principios nucleares de la organización castrense: la unidad, la jerarquía y la disciplina.

En suma, a la vista de las reflexiones precedentes, bien puede defenderse la naturaleza institucional de las Fuerzas Armadas, y, en coherencia con ello y con algunas de las tomas de posición en el debate constituyente, entender que esta naturaleza fue otra de las razones atendidas por los constituyentes a la hora de incluir el tratamiento constitucional de las Fuerzas Armadas en el Título Preliminar.

\subsection{Reflexión final}

A la vista de lo expuesto inmediatamente antes, nuestra primera afirmación creemos queda en alguna medida corroborada. Varias circunstancias confluyeron para desencadenar el singular tratamiento constitucional de las Fuerzas Armadas. Es evidente que el peculiar proceso de la transición debió influir y ello da fuerza a la hipótesis de que muchos constituyentes, consciente o inconscientemente, optaron por incorporar a la norma suprema una realidad preexistente. Pero es seguro que también debieron ejercer un peso considerable en esta decisión perfectamente consensuada las altas misiones que la Constitución atribuye a las

\footnotetext{
103 José Rojas Caro: Derecho disciplinario militar, Tecnos, Madrid, 1990, p. 42.

114 STC 180/1985, de 19 de diciembre, fund, jur. 2.

105 El valor primordial que la subordinación jerárquica y la disciplina tienen en la institución militar hacen, a juicio del Alto Tribunal (STC 44/1983, de 24 de mayo, fund. jur. 1), que en su ámbito el procedimiento disciplinario no pueda, por su propia naturaleza, quedar sometido a las garantías procesales generalmente reconocidas para los procesos judiciales, pues su razón de ser reside en la prontitud y rapidez de la reacción frente a las infracciones de la disciplina militar.

106 Francisco FERNÁNDEZ SEGADO: "Las restricciones de los derechos de los militares desde la perspectiva del ordenamiento internacionaln, en Revista de Estudios Politicos, n. 64 (nueva época), abril-junio 1989, pp. 93 y ss.; en concreto, p. 97.
} 
Fuerzas Armadas. Y desde luego, creemos que la naturaleza institucional de los Ejércitos estuvo presente en el sentir de muchos constituyentes al adoptar la decisión que comentamos.

Ahora bien, llegados aquí hemos de significar que no creemos que la constitucionalización de las Fuerzas Armadas en el Título Preliminar y la admisión de la interpretación de que ello responde, en buena medida, a su naturaleza institucional, debe desencadenar como consecuencia jurídica inmediata la protección constitucional de las Fuerzas Armadas a través de la técnica de la garantía institucional, como ha señalado LOPEZ GARRIDO $^{107}$. Por el contrario, concordamos plenamente con LOPEZZ RAMÓN ${ }^{108}$ cuando sostiene que las Fuerzas Armadas no disfrutan de la garantía institucional, pues no creemos que exista un núcleo o reducto indisponible por el legislador, quien goza de libertad para configurarlas como estime oportuno, en el respeto lógicamente de los dictados constitucionales.

En definitiva, la constitucionalización de las Fuerzas Armadas en el Título Preliminar carece, como señala Casado Burbano ${ }^{109}$, de especial significado jurídico, aunque, ciertamente, implique un "plus" respecto de otras instituciones del Estado, lo que se explica de modo muy particular tanto por las específicas singularidades de la institución como por las latas misiones que se le encomiendan.

\section{La composición de las Fuerzas Armadas}

El artículo 8, siguiendo el precedente del artículo 37 de la ley orgánica del Estado, precisa la composición de las Fuerzas Armadas, que quedan constituidas por el Ejército de Tierra, la Armada y el Ejército del Aire, separándose, sin embargo, de modo radical, del precepto que en este punto sirve de inspiración, por cuanto el citado artículo 37 integraba dentro de las Fuerzas Armadas a los Ejércitos de Tierra, Mar y Aire y a las Fuerzas de Orden Público. Con la Constitución, las ahora llamadas Fuerzas y Cuerpos de Seguridad quedan perfectamente deslindadas de las Fuerzas Armadas, al ser objeto del artículo 104 de la «Lex superior», ubicado en el Título IV, referente al Gobierno y a la Administración, que, además, con muy buen criterio, atribuye a las Fuerzas y Cuerpos de

\footnotetext{
107 Diego López Garrido: “La posición constitucional...", op. cit., pp. 959-961.

3108 Fernando LOPEz RAMÓN: La caracterización jurídica..., op. cit., pp. 375-376.

(10) Pablo CASAdo BURBANO: "Las Fuerzas Armadas en la nueva Constitución española", op. cit., p. 11.
} 
Seguridad unas misiones bien dispares de las encomendadas a las Fuerzas Armadas: proteger el libre ejercicio de los derechos y libertades y garantizar la seguridad ciudadana (art. 104.1 CE).

Esta cuestión se convertiría en una de las más controvertidas del artículo 8, especialmente en su debate en el Congreso de los Diputados. Como ya tuvimos oportunidad de reseñar, de las siete enmiendas presentadas, seis afectaban a la composición de las Fuerzas Armadas de una u otra forma. De esas seis enmiendas, tres de ellas (la n. ${ }^{\circ} 2$, del Sr. Carro Martínez; la n. ${ }^{\circ} 35$, del Sr. de la Fuente y de la Fuente, y la n. ${ }^{\circ} 63$, del Sr. Fernández de la Mora) postulaban la supresión de la referencia constitucional a la composición de las Fuerzas Armadas. Una cuarta (la enmienda n. ${ }^{\circ}$ 64, del Sr. Letamendía, en el texto del art. 102, alternativo al art. 10 del anteproyecto, cuya supresión pedía) también propugnaba que se guardara silencio sobre la composición de las Fuerzas Armadas, si bien, implícitamente, parecían diferenciarse en ella con nitidez las Fuerzas Armadas de las de Orden Público. Las dos restantes enmiendas defendían que las Fuerzas Armadas abarcasen también, en un caso (enmienda n. ${ }^{\circ} 38$, del Sr. Gómez de las Roces), a «los demás cuerpos o institutos que reciban consideración militar", y en el otro (enmienda n. ${ }^{\circ}$ 463, del Grupo Parlamentario Mixto, suscrita por el Sr. Morodo), a «las Fuerzas de Orden Público». También el Grupo Parlamentario de Alianza Popular presentó un voto particular al anteproyecto de Constitución, por el que se pretendía la supresión del artículo 8 de la referencia a la composición de las Fuerzas Armadas.

En la Comisión de Asuntos Constitucionales del Congreso, el Sr. Fraga defendería el voto particular de su grupo aduciendo que ni presentaba naturaleza constitucional la enumeración de los integrantes de las Fuerzas Armadas, ni la evolución técnica de los futuros Ejércitos hacía aconsejable esta enumeración ${ }^{110}$, argumentación a la que el propio diputado añadiría, ya en su intervención ante el Pleno de la Cámara Baja ${ }^{111}$, la de que tal enumeración quizá no dejaba clara «la situación de unidades como la Guardia Civil, que forman parte claramente, por tradición y derecho, de las Fuerzas Armadas".

En el turno en contra, el Sr. Llorens Barges, diputado centrista, se mostraría partidario ${ }^{112}$ de que fuese la legislación de desarrollo constitucional la que hiciese las matizaciones precisas respecto de la Guardia Civil, mientras que el diputado socialista Sr. Solana Madariaga (Luis)

\footnotetext{
111 DSCD, n. ${ }^{\circ} 67,16$ de mayo de 1978, pp. 2376-2377.

11 DSCD, n. $.^{\circ} 104,5$ de julio de 1978, pp. 3880-3881.

112 DSCD, n. ${ }^{\circ} 104,5$ de julio de 1978, pp. 3881-3882.
} 
manifestaba que aunque la Guardia Civil tenía que participar en la defensa, como todos los demás ciudadanos, sólo las Fuerzas Armadas integran al pueblo en la defensa y sólo ellas por lo tanto tienen que estar recogidas en la Constitución ${ }^{113}$.

En el Senado, el tema pasaría casi inadvertido. Sólo una enmienda (la n. ${ }^{\circ} 172$, del Sr. Gamboa Sánchez-Barcaiztegui) propugnaría que en las Fuerzas Armadas quedasen integrados los institutos y cuerpos armados sometidos a disciplina militar, posición que se justificaría en que tales cuerpos e institutos también participan de la misión general que el precepto encomienda a las Fuerzas Armadas ${ }^{114}$. La cuestión apenas sí suscitaría debate en la Cámara Alta.

Resulta una obviedad que la problemática de fondo latente en la composición de las Fuerzas Armadas era la del posible encaje en aquéllas de la Guardia Civil, cuerpo que tradicionalmente ha venido formando parte del Ejército de Tierra, como ya lo reconociera su ley constitutiva de 1878 y la ley adicional a la misma de 1889.

Ciertos sectores doctrinales han interpretado que la Constitución no se ha pronunciado sobre la cuestión de la pertenencia de la Guardia Civil a las Fuerzas Armadas, correspondiendo por tanto al legislador ordinario, en su caso, la decisión al respecto ${ }^{115}$, mientras que otros ${ }^{116}$ han avanzado que el espíritu del artículo 8.1 no tiene intencionalidad orgánica limitativa, en cuanto se puede afirmar que los redactores del artículo y las Cortes que lo aprobaron no consideraron tal problema, y su idea al enumerar los componentes de las Fuerzas Armadas fue diferenciarlas de las de Orden Público. No han faltado quienes han criticado la taxatividad de la enumeración ${ }^{117}$.

No nos sentimos identificados con las opiniones inmediatamente precedentes, sino que creemos, con BLANCO VALDÉs, que el principio establecido en la Constitución en materia de composición de las Fuerzas Armadas no es sino el de que aquéllas están constituidas exclusivamente por el Ejército de Tierra, la Armada y el Ejército del Aire ${ }^{118}$. Y es como,

\footnotetext{
113 DSCD, n. ${ }^{\circ} 104,5$ de julio de 1978, pp. 3883-3884.

114 DSS, n. ${ }^{\circ} 41,22$ de agosto de 1978, pp. 1712-1713.

115 Pablo CASADO BURBANO: Iniciación al Derecho constitucional militar, Editorial Revista de Derecho Privado, Madrid, 1986, p. 27. Análoga es la posición de Oscar Alzaga (en Comentario sistemático..., op. cit., p. 129), para quien nuestras Constituyentes prefirieron dejar la cuestión de la condición de la Guardia Civil a su tratamiento en la legislación ordinaria.

116 Juan Cano Hevia: "Fuerzas Armadas", en J. J. González Encinar (dir.), Diccionario del sistema politico español Akal Editor, Madrid, 1984, pp. 349 y ss.; en concreto, p. 357.

117 José M.' Lafuente Balle: El rey y las Fuerzas Armadas, op. cit., p. 345.

118 Roberto BLANCO VALDES: La ordenación constitucional de la defensa, op. cit., pp. 77-78.
} 
como afirma Trillo-FigueroA ${ }^{119}$, la Constitución, al acoger el término "Fuerzas Armadas", lo adaptó a los enunciados del Estado democrático, a cuyo efecto no incluye ya a las Fuerzas de Orden Público -ahora Fuerzas y Cuerpos de Seguridad-, integradas por la ley orgánica del Estado de 1967, como ya advertimos, dentro de las Fuerzas Armadas, cuerpos que, aun pudiendo estar sometidos a disciplina militar, no forman parte, sin embargo, de las Fuerzas Armadas.

Esta interpretación se sustenta no ya en la dicción literal del artículo 8.1, sino también en el propio itinerario del precepto, que nos revela de modo inequívoco no sólo el rechazo del constituyente a incorporar los Cuerpos y Fuerzas de Seguridad a las Fuerzas Armadas, sino incluso su deseo patente de explicitar quiénes integran las Fuerzas Armadas, frente a los que postulaban la indefinición del constituyente en este punto. Más aún, una interpretación sistemática del artículo 8 y del artículo 104 corrobora esta tesis. El constituyente ha procedido a deslindar con bastante nitidez las funciones constitucionales de las Fuerzas Armadas y de las Fuerzas y Cuerpos de Seguridad. Como advierte Cano Hevia ${ }^{120}$, la Constitución deja bien claro que no quiere que los Ejércitos asuman funciones características de las Fuerzas de Orden Público. Este deslinde funcional no queda desvirtuado por el hecho de que el artículo 2.2 de la ley $2 / 1985$, de 21 de enero, sobre Protección Civil, prevea la colaboración de las Fuerzas Armadas en la protección civil, dando cumplimiento a las misiones que se les asignen, previa solicitud a las autoridades competentes y en tiempo de paz. Y tampoco resulta desvirtuado por la circunstancia de que la Guardia Civil, en tiempo de paz asimismo, pueda ser encargada del cumplimiento de las misiones de carácter militar que por su naturaleza se le encomienden (art. 38 de la ley orgánica 6/1980) ${ }^{121}$. Y evidentemente, ese deslinde funcional ha de tener su correspondencia orgánica, desde el momento en que el artículo 8.1 enuncia quiénes integran las Fuerzas Armadas ${ }^{122}$.

Ciertamente, como el Tribunal Constitucional ha puesto de relieve $^{123}$, no puede decirse que la Constitución establezca como dos bloques institucionales rígidos e incomunicables los incluidos en los artículos 8

\footnotetext{
119 Federico Trillo-FigueroA M-CONDE: «Las Fuerzas Armadas en la Constitución espanolam, op. cit., p. 110.

120 Juan Cano Hevia: “Fuerzas Armadas”, op. cit., p. 349.

121 En análogo sentido, Jorge de Esteban y Pedro J. Gonzalez-Trevijano: Curso..., III, op. cit., p. 358 .

${ }_{122}$ En igual sentido, Fernando LOPEZ RAMON: La caracterización juridica de las Fuerzas Armadas, op. cit., pp. 311-312.

123 STC 194/1989, de 16 de noviembre, fund. jur. 3.
} 
y 104, pues el propio texto constitucional prevé y permite (arts. 28.1 y 29.2) la existencia de institutos armados y de cuerpos sometidos a disciplina militar, pero, en todo caso, como el mismo Alto Tribunal precisa, distintos a las Fuerzas Armadas, con lo que nuestra norma suprema reconoce así un tertium genus o una figura intermedia entre las Fuerzas Armadas y los Cuerpos de Seguridad no sometidos a disciplina militar.

El proyecto de ley orgánica por la que se regulan los criterios básicos de la defensa nacional y la organización militar ${ }^{124}$, en su artículo 35.1 disponía que: "La Guardia Civil es un cuerpo militar que, como tal, forma parte del Ejército de Tierra, dependiendo en los aspectos militares del Ministerio de Defensa, y en cuanto a sus funciones de orden y seguridad pública, del Ministerio del Interior.» Ello entrañaba, a nuestro modo de ver, una conculcación del espíritu, y aún diríamos incluso que de la propia letra, de la Constitución, pues aunque ésta formalmente no era alterada, al enmarcarse orgánicamente la Guardia Civil en el Ejército de Tierra, se venía a quebrar el deslinde entre Fuerzas Armadas y Fuerzas y Cuerpos de Seguridad llevado a cabo por el constituyente. Una enmienda del Grupo Parlamentario Socialista, en la que la Guardia Civil, pese a ser considerada como "cuerpo de estructura y organización militar», era desvinculada orgánicamente del Ejército de Tierra, quedando en dependencia alternativa del Ministerio de Defensa o del Ministerio del Interior, según los casos, está en la base misma del que habría de ser finalmente el artículo 38 de la ley orgánica 6/1980, que debe ser interpretado en conexión con el texto del artículo $9, \mathrm{~b} /$ de la ley orgánica $2 /$ 1986, de 13 de marzo, de Fuerzas y Cuerpos de Seguridad. De la interpretación conjunta de ambas previsiones pueden extraerse estas consecuencias:

1. a) La Guardia Civil, orgánicamente, no forma parte del Ejército de Tierra, por lo que, a diferencia de tiempos pretéritos, no puede ser considerada incluida dentro de las Fuerzas Armadas.

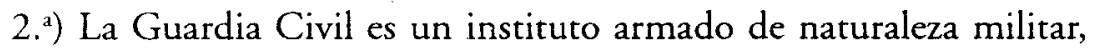
por lo que se sitúa como una suerte de figura intermedia entre el Cuerpo Nacional de Policía, que es un instituto armado de naturaleza civil, y las Fuerzas Armadas.

3. $\left.{ }^{2}\right)$ En tiempo de paz, la dependencia funcional de la Guardia Civil es doble: del ministro de Defensa, en el cumplimiento de las misiones de carácter militar que le encomienden el propio ministro o el Gobier-

124 Puede verse en BOCG, Congreso de los Diputados, serie A, n. ${ }^{\circ} 72-I, 21$ de septiembre de 1979. 
no, y del ministro del Interior, en el desempeño de las funciones relativas al orden y a la seguridad pública que la ley orgánica 2/1986 le atribuye.

$\left.4{ }^{2}\right)$ En tiempo de guerra y durante el estado de sitio, la Guardia Civil dependerá exclusivamente del ministro de Defensa.

A la vista de esta ordenación normativa, la cuestión que mayores dudas y problemas plantea es la atribución a la Guardia Civil de «misiones de carácter militar». Ciertamente, el artículo 14.3 de la ley orgánica 2/1986 habilita al ministro de Defensa para que disponga lo concerniente al régimen de ascensos y situaciones del personal, circunstancia que, sin embargo, no implica una dependencia orgánica de la Guardia Civil respecto de ese ministerio. Es cierto asimismo que durante bastante tiempo la Guardia Civil se ha regido por la normativa disciplinaria aplicable a las Fuerzas Armadas (ley orgánica 12/1985, de 27 de noviembre, del Régimen Disciplinario de las Fuerzas Armadas). Sin embargo, el artículo 15.1 de la ley orgánica 2/1986 determina que «la Guardia Civil, por su condición de instituto armado de naturaleza militar, a efectos disciplinarios, se regirá por su normativa específica». Esta determinación condujo al Tribunal Constitucional a significar ${ }^{125}$ que esta previsión legislativa «no puede quedar indefinidamente incumplida, dando pie para una aplicación transitoria, pero también indefinida, del régimen disciplinario militar». «El legislador -añadía el juez de la Constitución- debe ser fiel a su propósito, zanjando de una vez por todas las indefiniciones legislativas sobre la especificidad a estos efectos de la Guardia Civil, y regulando la materia disciplinaria de dicho instituto armado de un modo directo y positivo y no, como hasta ahora, por medio de técnicas de exclusión y de remisión.» La recomendación del Alto Tribunal al legislador surtiría un pronto efecto, al ser aprobada poco después de un año la ley orgánica $11 / 1991$, de 17 de junio, del Régimen Disciplinario de la Guardia Civil ${ }^{126}$.

Retornando a la problemática relativa a las «misiones de carácter militar», hay que señalar que ni la ley orgánica $6 / 1980$, ni la también ley orgánica 2/1986 precisan el alcance de tales misiones, si bien hay que recordar que dichas misiones deberán ser acordes con la naturaleza de la Guardia Civil. El silencio del legislador se hace más significativo, si cabe,

\footnotetext{
125 STC 194/1989, de 16 de noviembre, fund. jur. 4.

126 Sobre ella, cfr. José Luis Rodriguez-Villasante y Prieto (coord.), Comentarios a la ley disciplinaria de la Guardia Civih Ministerio del Interior, Madrid, 1993. Asimismo, Antonio MILLÁN GaRRIDO: Régimen disciplinario de la Guardia Civil Editorial Trotta, Madrid, 1992.
} 
si se advierte que los artículos 11 y 12 de la ley orgánica de Fuerzas y Cuerpos de Seguridad enumeran con todo detalle las actuaciones relacionadas con el mantenimiento del orden y la seguridad pública, función en la que, como se afirma en el preámbulo de la ley (punto III, b/), deben concentrarse, en su mayor parte, las misiones y servicios asumibles por la Guardia Civil, que, como Cuerpo de Seguridad, centra su actuación en el ejercicio de funciones propiamente policiales.

La ley orgánica 2/1986 precisa (art. 7.3) que la Guardia Civil sólo tendrá la consideración de "fuerza armada" en el cumplimiento de las misiones de carácter militar que se le encomienden, de acuerdo con el ordenamiento jurídico, debiendo complementarse esta determinación con la del artículo 10 de la ley orgánica 13/1985, de 9 de diciembre, de Código Penal Militar, de conformidad con el cual: «A los efectos de este Código se entenderá que constituyen fuerza armada los militares que, portando armas y vistiendo el uniforme, presten servicios legalmente encomendados a las Fuerzas Armadas, reglamentariamente ordenados, así como, en las mismas circunstancias, los miembros de la Guardia Civil, cuando prestando servicio propio de su instituto, así lo disponga la ley a la que se refiere el artículo 104.2 de la Constitución» (esto es, la ley orgánica 2/1986). Esto supone, por ejemplo, que la desobediencia de órdenes provenientes de una fuerza armada es tipificada específicamente como delito por el Código Penal Militar (art. 85), con lo que ello entraña de competencia de la jurisdicción castrense.

\section{Las misiones de las Fuerzas Armadas}

La defensa de la colectividad, como ya tuvimos oportunidad de significar, es la idea que da su razón de ser a las Fuerzas Armadas ${ }^{127}$. "La razón de ser de los Ejércitos es la defensa militar de España», dice el artículo 3 de las Reales Ordenanzas para las Fuerzas Armadas, acogiendo un concepto, el de defensa militar, no estrictamente coincidente con el de defensa nacional, quizá por la mayor amplitud de este último ${ }^{128}$.

\footnotetext{
A juicio de Federico Trillo-Figueroa («Las Fuerzas Armadas en la Constitución española”, op. cit., p. 116), la defensa nacional es la idea directriz de la institución militar. Es el concepto expresivo de lo que Hauriou llama «idea de la obra a realizar, que expresa a la vez el fin y los medios a emplear para alcanzarlo".

128 El concepto de "defensa nacional" se nos ofrece como repleto de matices en los que la preservación de todos y cada uno de los elementos distintivos del Estado de Derecho que afirma la Constitución cobra entidad por sí mismo: no solamente el territorio (la soberanía política y militar sobre el mismo, la integridad territorial del art. 8.1 de la Constitución), sino también por lo tanto el ordenamiento constitucional y los valores adyacentes al concepto de interés nacional.
} 
El concepto de "defensa nacional» sustituyó al más añejo concepto de "guerra", respondiendo quizá, como recuerda DiEz ALEGRfA ${ }^{129}$, a aquella expresión de CLAUSEWITZ de que la guerra se hace con toda la potencia de la nación ${ }^{130}$. Con el devenir del tiempo, el concepto de guerra total, fruto de la tecnificación de los armamentos y, sobre todo, de la irrupción del arma nuclear, ha consolidado el concepto de «defensa nacional». Este tendrá su recepción constitucional entre nosotros en la Constitución de 1931, cuyo artículo 14.7 consideraba de la exclusiva competencia del Estado español la legislación y ejecución directa en materia de Ejército, Marina de guerra y defensa nacional.

La defensa nacional, a tenor del inciso segundo del artículo 2 de la ley orgánica 6/1980, tiene por finalidad garantizar de modo permanente la unidad, soberanía e independencia de España, su integridad territorial y el ordenamiento constitucional, protegiendo la vida de la población y los intereses de la patria. Este paralelismo entre el precepto a que acabamos de aludir y el artículo 8.1 de la Constitución es revelador de la asunción por la norma constitucional de los fines básicos de la defensa nacional.

El elemento central e insustituible de la defensa nacional lo forman las Fuerzas Armadas, lo que se explica, como razona Fernandez Espe$\mathrm{SO}^{131}$, por varias razones: poseen la capacidad superior de acción por la fuerza, están en condiciones de utilizarla en la forma más adecuada, garantizan la continuidad sin interrupciones del esfuerzo defensivo y aseguran también una estructura básica a partir de la cual se puede ampliar o modificar el sistema de defensa para hacer frente a las necesidades propias de cada momento.

Sin embargo, el concepto de "defensa nacional" desborda la organización y acción de los Ejércitos. La definición que de la defensa nacional da el inciso primero del artículo 2 de la ley orgánica 6/1980 corrobora

Juan Fernando Lopez Agullar: "Defensa, interés nacional y seguridad colectiva” (Acotaciones conceptuales desde el ordenamiento constitucional español), en el colectivo Constitución y Derecho priblico (Estudios en homenaje a Santiago Varela), Tirant lo Blanch, Valencia, 1995, pp. 241 y ss.; en concreto, p. 246.

129 Manuel Díez Alegría: "El cambio en el gobierno de la defensa nacional", en Anales de la Real Academia de Ciencias Morales y Políticas, n. ${ }^{\circ}$ 52, 1975. Cit. por Luis SANCHEz AGESTA: El sistema politico de la Constitución española de 1978, Editora Nacional, Madrid, 1980, pp. 249250 .

130. Recordemos que para Clausewitz, la guerra no era sino la simple continuación de la política con otros medios. Carlos von ClausewiTz: De la guerra, Ediciones Ejército, 2.* ed., Madrid, 1980, p. 43 (Capítulo 1 del Libro I, epígrafe XXIV).

131 Carlos FERNÁNDEZ ESPESO: "Defensa nacional y seguridad nacional", en el colectivo Libertades públicas y Fuerzas Armadas, Ministerio de Educación y Ciencia e Instituto de Derechos Humanos, Madrid, 1985, pp. 797 y ss.; en concreto, p. 800. 
esta apreciación, pues la defensa nacional, como ya vimos en un momento anterior, se concibe como «la disposición, integración y acción coordinada de todas las energías y fuerzas morales y materiales de la Nación, ante cualquier forma de agresión». De todo ello, SÁNCHEZ AGESTA ha deducido ${ }^{132}$ que la función de defensa es un contenido central de la función de gobierno, y que corresponde al órgano de esta función, al Gobierno, dirigir la política de defensa y las Fuerzas Armadas ${ }^{133}$.

El ejercicio efectivo de la defensa conduce en su modalidad extrema al empleo de la fuerza como último recurso con el que enfrentar una agresión. Es aquí donde entran en juego las Fuerzas Armadas ${ }^{134}$, pero no conviene olvidar la función disuasoria que las mismas cumplen, y que de alguna manera supone otra modalidad de ejercicio de la fuerza. La disuasión entraña hacer ver al eventual agresor que no podrá conseguir sus objetivos al tener que hacer frente a un sistema de defensa que hará inútil la agresión o supondrá al agresor un coste demasiado elevado. De esta forma, bien puede decirse que las Fuerzas Armadas, elemento central de la defensa nacional, encuentran su razón de ser en la defensa militar, cuyas dos facetas complementarias son la acción, esto es, el empleo de la fuerza, y la disuasión.

A la vista de todo lo expuesto, parece claro que esta función de defensa que asumen las Fuerzas Armadas ha de ser entendida como defensa material, pues, al margen ya de su vertiente disuasoria, implica un llamamiento al empleo de la fuerza institucionalizada, sin que en modo alguno, como ya hemos dicho en varias ocasiones, pueda entenderse que ello supone la creación de un poder autónomo de defensa radicado en las propias Fuerzas Armadas.

Efectuadas las reflexiones que preceden, hemos de centrarnos ya en las misiones que el artículo 8.1 encomienda a nuestras Fuerzas Armadas. Son éstas: $1 .^{a}$ ) garantizar la soberanía e independencia de España; $2 .^{2}$ ) defender su integridad nacional, y $3 .{ }^{a}$ ) defender el ordenamiento constitucional.

\footnotetext{
Luis SánCHez Agesta: El sistema político..., op. cit., p. 250.

No es posible hoy, en el nivel de nuestro tiempo, concebir a la "defensa nacional" como una noción técnica, profesionalmente aislada, de una corporación o estamento militar, aunque éste esté preparado para encuadrar a la "nación en común». En tales términos se manifiesta Daniel VILLAGRA BLANCO: "Ley orgánica por la que se regulan las bases de la defensa nacional y la organización militar", en Cuadernos de Documentación, n. ${ }^{\circ} 35$, Secretaría General Técnica, Presidencia del Gobiernoo, Madrid, 1980, p. 32.

${ }_{134}$ El primer deber del Ejérciro de hoy -dirá DIEZ ALEGRIA (en Ejército y sociedad, op. cit., p. 49) - es el de constituir el medio coactivo del Estado, la fuerza organizada a disposición de la comunidad.
} 


\subsection{La garantía de la soberanía e independencia de España}

Estamos sin ningún género de dudas ante la misión más tradicional de las Fuerzas Armadas. Recordemos que ya el artículo 356 de la Constitución de Cádiz atribuía a la fuerza militar nacional permanente la defensa exterior del Estado (además de la conservación del orden en el interior).

A través de esta defensa exterior del Estado se pretende salvaguardar dos de los elementos configuradores del mismo: la población y la soberanía. La determinación constitucional del artículo 1.2, que convierte al pueblo en el origen de todo poder, puede reconducir el sentido de esta misión, que bien podría ser entendida que se orienta a salvaguardar la residencia de la soberanía en el pueblo español y la libre capacidad de autodeterminación del mismo en el orden internacional que aquélla entraña.

La doctrina ${ }^{135}$ ha interpretado que el término "garantizar", que aquí se emplea, en contraste con el de "defender", que se utiliza en las dos restantes misiones, supone una actividad de preparación y vigilancia, que llevan primariamente a la idea de disuasión y sólo después a la de defensa, como reacción frente a una agresión. Ello sintoniza con algunas de las reflexiones que tuvimos oportunidad de hacer al hilo de la enmienda n. ${ }^{\circ} 448$, del senador Sr. Xirinacs ${ }^{136}$. Nuestra pertenencia a la ONU obliga al Estado español a abstenerse de recurrir a la amenaza o al uso de la fuerza contra la integridad territorial o independencia política de cualquier Estado, lo que entraña que el recurso a las Fuerzas Armadas a efectos del empleo material de la fuerza ha de entenderse como el último recurso con el que enfrentar una agresión exterior. Asimismo, ha de recordarse una vez más que la nación española, en el preámbulo de su Carta Magna, manifiesta solemnemente su voluntad de "colaborar en el fortalecimiento de unas relaciones pacíficas (y de eficaz cooperación) entre todos los pueblos de la Tierran. Y por si todo este instrumental de argumentos no fuera suficiente, podría recordarse que en el Estatuto del Consejo de Europa, hecho en Londres el 5 de mayo de 1949, al que España se adhirió el 22 de noviembre de 1977, los países signatarios del mismo manifiestan estar convencidos de que la consolidación de la paz, basada en la justicia y en la cooperación internacional, es de interés vital para la preservación de la sociedad humana y de la civilización.

\footnotetext{
135 Roberto GonZÁlez VAlLEJO: “La defensa nacional, las Fuerzas Armadas y la Constitución española de 1978", en el colectivo Posición constitucional de las Fuerzas Armadas en Iberoamérica y en España, op. cit., pp. 123 y ss.; en concreto, p. 125.

136. Véase nota $n .{ }^{\circ} 17$.
} 
Todo ello nos lleva a entender que nuestra política de defensa no sólo ha de velar para que la defensa nacional, como establece el artículo 3 de la ley orgánica $6 / 1980$, constituya un conjunto armónico que proporcione una efectiva seguridad nacional, sino que ha de estar asimismo orientada al mantenimeinto de la paz y de la seguridad en el mundo.

Creemos finalmente innecesario insistir sobre la instrumentalidad de la institución castrense respecto del Estado en el ejercicio de estas misiones. El artículo 63.3 de la Constitución atribuye al rey, previa autorización de las Cortes Generales, declarar la guerra y hacer la paz, atribución que, en el marco de la monarquía parlamentaria, forma política de nuestro Estado, no entraña capacidad decisoria regia alguna. En cualquier caso, la utilización de las Fuerzas Armadas para la defensa exterior del Estado no queda limitada al caso de la declaración formal de guerra ${ }^{137}$.

\subsection{La defensa de la integridad territorial}

La integridad territorial presenta una doble proyección, como la casi totalidad de la doctrina admite: exterior e interior. Ya incluso en el debate constituyente el diputado socialista Sr. Múgica Herzog ${ }^{138}$ puso de relieve que para su grupo la defensa de la integridad territorial «tiene una doble connotación: la que procede de que un poder extranjero no podrá agredirnos impunemente con el propósito de apropiarse de parte del territorio nacional, y la que se deriva de la firme voluntad de la gran mayoría de los ciudadanos que habitan las comunidades que integran España, de seguir siendo españoles con todas sus consecuencias».

La proyección externa, es evidente, pretende hacer frente a cualquier intento de agresión por parte de otro Estado con vistas a apropiarse de una parte de nuestro territorio. En cualquier caso, parece claro que la integridad territorial, desde esta perspectiva externa, está protegida por la primera de las misiones atribuidas a las Fuerzas Armadas, pues cualquier ataque externo a nuestra integridad territorial deberá verse al unísono como un ataque a nuestra soberanía e independencia ${ }^{139}$.

La proyección interna pretende impedir una secesión o fragmentación de nuestro territorio, en el bien entendido de que una agresión interna a

\footnotetext{
137 En igual sentido, Fernando LOPEZ RAMÓN: La caracterización jurídica de las Fuerzas Armadas, op. cit., p. 319.

138 DSCD, n. 67,16 de mayo de 1978, p. 2379.

13.) En análogo sentido, Jorge de Esteban y Pedro J. Gonzalez-Trevijano: Curso de Derecho constitucional III, op. cit., p. 360 .
} 
la integridad territorial lo será, al unísono, al ordenamiento constitucional ${ }^{140}$, pues, como prevé el artículo 2 de nuestra Magna Carta política, «la Constitución se fundamenta en la indisoluble unidad de la Nación española". Es precisamente por ello mismo por lo que se rechazaron tanto en el Congreso (enmienda ${ }^{\circ}{ }^{\circ} 35$, del Sr. de la Fuente y de la Fuente), como en el Senado (enmiendas números 172, del Sr. Gamboa Sánchez-Barcaiztegui; 217, del Sr. Matutes Juan; 226, del Sr. Carazo Hernández, y 382, del Sr. Díez Alegría), diferentes enmiendas encaminadas todas ellas a incluir la garantía de la unidad entre las misiones encomendadas a las Fuerzas Armadas. Como señalara el senador centrista Sr. González Seara ${ }^{141}$, "cuando se dice que a las Fuerzas Armadas corresponde la defensa del ordenamiento constitucional, ahí está comprendida la defensa de la unidad de España que se mantiene en algunas enmiendas, porque el ordenamiento constitucional establece claramente, sin ninguna duda, la unidad indisoluble de la Nación españolan.

En esta misma dirección, y como ya hemos tenido oportunidad de reseñar con anterioridad, el inciso segundo del artículo 2 de la ley orgánica $6 / 1980$, precisa como finalidad de la defensa nacional «garantizar de modo permanente la unidad, soberanía e independencia de España, su integridad territorial y el ordenamiento constitucional $[\ldots] . .^{142}$.

\subsection{La defensa del ordenamiento constitucional}

La atribución a las Fuerzas Armadas de la misión de defensa del ordenamiento constitucional es habitual encontrarla, como significara OeHLING ${ }^{143}$, en las Constituciones de aquellos países en cuya historia polírica ha sido frecuente la incursión del establecimiento armado, o en aquellos otros en que se manifiesta el ánimo temeroso de tal posibilidad.

El precedente más inmediato lo encontramos en el artículo 37 de la ley orgánica del Estado de 1967, que atribuía a las Fuerzas Armadas la defensa del orden institucional, aunque ya la ley Adicional a la Ley Cons-

\footnotetext{
14t En igual sentido, Roberto BLANCO VALDES: La ordenación constitucional de la defensa, op. cit., pp. 70-71.

${ }_{1+1}$ DSS, n." 41, 22 de agosto de 1978, pp. 1714-1715.

142 A juicio, harto discutible ciertamente, de Suárez Pertierra (en «Regulación jurídicoconstitucional de las Fuerzas Armadas", op. cit., p. 2387), la idea de unidad no debe sujetarse de una manera directa al criterio uintegridad territorial", que en los supuestos constitucional y orgánico se utilizan.

14.3 Hermann Oehling: La función política del Ejército, Instituto de Estudios Políticos, Madrid, 1967, p. 70.
} 
titutiva del Ejército, de 19 de julio de 1889, atribuía al Ejército en su artículo 1 la finalidad, entre otras primordiales, de mantener el imperio de la Constitución y las leyes. GARCí ARIAS ${ }^{144}$ entendería la defensa del orden institucional como una función política suprema, que podríamos denominar disuasoria, de las Fuerzas Armadas, no sólo por ser éstas el último garante del orden institucional español, sino también su custodio. Y consideraría disuasoria esta función política eminente y excepcional de las Fuerzas Armadas porque el término viene a tener el mismo significado que ofrece la disuasión nuclear en el orden internacional.

Esta defensa del ordenamiento tiene una proyección inequívocamente interna, esto es, los potenciales agresores no provienen del exterior sino del interior, pues es obvio que un atentado externo contra nuestro ordenamiento constitucional sería reconducible a un ataque contra la soberanía, la independencia $o$, incluso, la integridad territorial ${ }^{145}$.

La doctrina ha entendido que el ordenamiento constitucional no ha de limitarse sólo a la letra de la Constitución, sino que se extiende a los principios que la inspiran, institucionalizando así en los Ejércitos la función política de defensa en el orden interno ${ }^{146}$.

Como ha señalado GARCIA DE ENTERRIA ${ }^{147}$, el ordenamiento funciona necesariamente como un sistema total, desde el momento en que su función es regular la totalidad del núcleo social del que surge. Del ordenamiento ha de predicarse, pues, un sentido de totalidad, acogido por lo demás por nuestra Constitución, entre otros, en los artículos 1.1 y 9.1. De ahí que concordemos con la apreciación de BALLBE ${ }^{148}$, de que las Fuerzas Armadas pueden y deben intervenir en la defensa del ordenamiento constitucional, bajo las directrices del Gobierno, no cuando se ponga en peligro algún aspecto parcial o concreto del "orden" constitucional, sino cuando esté en peligro el "ordenamiento", es decir, el conjunto del sistema institucional y normativo. Ello, a su vez, supone la radical exclusión del recurso gubernamental a las Fuerzas Armadas cuando lo que esté en peligro sea el orden, la seguridad ciudadana, a diferencia de lo acontecido históricamente en nuestro país, y a diferencia también,

${ }^{344}$ Luis GARCIA ARIAS: “Las Fuerzas Armadas en la ley orgánica del Estado», op. cit., p. 148.

145 En igual sentido Roberto L. BLANCO VALDÉs: La ordenación constitucional de la defensa, op. cit., p. 71 .

146 José Manuel Serrano AlberCa: "Comentario al artículo 8.1", en Fernando Garrido Falla (dir.), Comentarios a la Constitución, Civitas, 2. ${ }^{2}$ ed., Madrid, 1985, pp. 116 y ss.; en concreto, p. 121.

147 Eduardo García de EnTERria y TOMÁs-Ramón Fernández: Curso de Derecho administrativo, I, Civitas, 4. ${ }^{2}$ ed., Madrid, 1986, pp. 62-63.

148 Manuel BallBé: Orden puiblico y militarismo..., op. cit., p. 463. 
por ejemplo, de la previsión constitucional (art. 79) austriaca, que posibilita, como ya dijimos con anterioridad, que el Ejército federal, a instancia de la legítima autoridad civil, pueda ser llamado para mantener el orden y la seguridad en el interior.

Existe una generalizada opinión doctrinal ${ }^{149}$ en el sentido de que la defensa del ordenamiento constitucional es una defensa de carácter material, cuya naturaleza es por ello mismo política, bien diferenciada de la defensa jurídica, que se encomienda al Tribunal Constitucional.

De igual forma, hay coincidencia ${ }^{150}$ en la naturaleza excepcional y eminentemente disuasoria de esta misión que se encomienda a las Fuerzas Armadas. Y es una evidencia asimismo el carácter instrumental de las Fuerzas Armadas ${ }^{151}$. Como señala VeRGOTTINI ${ }^{152}$, el principio de intervención de las Fuerzas Armadas exclusivamente previa petición del poder político, no es sino una especificación de la naturaleza meramente ejecutiva de los poderes propios de las autoridades castrenses, y se refiere no sólo a la intervención en las relaciones internacionales del Estado, sino, sobre todo, a las relaciones internas.

Ahora bien, llegados aquí surge un problema de interés: ¿dispone el Gobierno de la libre capacidad de disposición sobre las Fuerzas Armadas con vistas a su utilización para la defensa del orden constitucional?

LOPEZ RAMÓN ${ }^{153}$, en una postura más bien minoritaria, entiende con carácter general que además de en el estado de sitio, la posibilidad de que las Fuerzas Armadas intervengan para el cumplimiento de las misiones encomendadas por el artículo 8.1 (también, pues, para la defensa del ordenamiento constitucional) permanece abierta, en manos de la autoridad política a quien corresponda la disposición efectiva de los Ejércitos (el Gobierno, pues a él se atribuye el poder de disposición de las Fuerzas Armadas, ex art. $97 \mathrm{CE}$ ). Ésa es, a juicio del citado autor, la única solución coherente con el contenido del texto constitucional, que no encauza necesariamente por la vía del estado de sitio el uso de las Fuerzas Armadas. Enumera misiones de las Fuerzas Armadas, misiones que éstas

\footnotetext{
149) Así, entre otros autores, Federico Trillo-Figueroa: «Las Fuerzas Armadas en la Constitución...,, op. cit., p. 120; Jorge DE Esteban y Pedro J. GonzAlez-Trevijano: Curso..., III, $o p$. cit., p. 361, y Gustavo SuÁrEz PerTIERRA: «Regulación jurídico-constitucional de las Fuerzas Armadas", op. cit., p. 2387.

15". Jorge de Esteban y Pedro J. Gonzalez-Trevijano: Curso..., III, op. cit., p. 360. José Manuel Serrano Alberca: "Comentario al artículo 8.1 de la Constitución", op. cit., p. 121.

151 La mera declaración que, en este sentido, hace el art. 8. CE, señala CASADO BURBANo ("Las Fuerzas Armadas en la nueva...», op. cit., p. 16), no tiene otro alcance ni otro significado que el exclusivamente instrumental y disuasorio.

${ }_{152}$ Giuseppe DE VeRGOTTINI: Derecho constitucional comparado, op. cit., pp. 296-297.

193 Fernando LÓpZ RAMÓN: La caracterización juridica..., op. cit., p. 324.
} 
llevan a cabo en la forma decidida por el órgano político que puede disponer de ellas ${ }^{154}$.

Sin embargo, la mayor parte de la doctrina no coincide con la opinión precedente. Y así, ALZAGA ${ }^{155}$ cree que la defensa del orden constitucional que corresponde a las Fuerzas Armadas es a través de las funciones que, llegado el caso, deba asumir, declarado el estado de sitio. También CRUZ VILLALON ${ }^{156}$ considera que la institución del estado de sitio es el instrumento a través del cual las Fuerzas Armadas pueden ser llamadas por el Congreso de los Diputados a colaborar, bajo las órdenes del Gobierno, en el rechazo de una agresión interna contra el ordenamiento constitucional de España. Para Trillo-FigueroA ${ }^{157}$, es a través del estado de sitio, con sometimiento al Gobierno, y en los términos que fije el Parlamento, como se instrumentaliza la función de defensa del ordenamiento constitucional por las Fuerzas Armadas. Y en idéntica dirección, BLANCO VALDES ${ }^{158}$ cree que sólo declarado el estado de sitio es posible constitucionalmente la intervención interna de las Fuerzas Armadas ${ }^{159}$.

Por nuestra parte, como ya tuvimos oportunidad de sefialar tiempo atrás ${ }^{160}$, el estado de sitio es el procedimiento necesario a cuyo través se canaliza la participación de las Fuerzas Armadas en la defensa del ordenamiento constitucional español. No otro significado ha de darse al artículo 32.1 de la ley orgánica 4/1981, de los estados de alarma, excepción y sitio, que, al contemplar los supuestos de hecho que habilitan para la declaración de este estado, reproduce miméticamente la previsión constitucional del artículo 8.1, lo que nos lleva a la conclusión de que el legislador, en sede orgánica, ha querido limitar el poder de dispo-

\footnotetext{
154 Análoga es la posición de Luis SANChez Agesta (en "La Constitución y las Fuerzas Armadas", en Primeras Jornadas Fuerzas Armadas-Universidad, CESEDEN, Madrid, 1982, pp. 147 y ss.; en concreto, p. 151), quien cree que el estado de sitio no agota enteramente la participación de las Fuerzas Armadas en la defensa del ordenamiento constitucional bajo la autoridad del Gobierno.

155 Oscar Alzaga: Comentario sistemático..., op. cit., p. 130.

156 Pedro Cruz Villalón: "El nuevo derecho de excepción" (Ley orgánica 4/1981, de 1 de junio), en Revista Española de Derecho Constitucional, n. 2 , mayo-agosto 1981, pp. 93 y ss.; en concreto, p. 101.

157 Federico Trillo-FigueroA: “Las Fuerzas Armadas...”, op. cit., p. 124.

158 Roberto BLANCO VALDEs: La ordenación coonstitucional de la defensa, op. cit., p. 72.

15.) Manuel BALLBE (en Orden público y militarismo..., op. cit., p. 463) cree que la intervención de las Fuerzas Armadas en defensa del ordenamiento constitucional sólo se puede dar en el supuesto de que previamente se haya declarado el estado de excepción o de sitio previstos en el art. $55 \mathrm{CE}$, opinión ciertamente harto discutible, por lo que al estado de excepción atañe.

160) Francisco FERNÁNDEZ SEGADO: «La participación militar en el estado de sitio y el modelo de régimen democráticom, en Revista de Derecho Público, n. ${ }^{\text {o }}$ 96-97, julio-diciembre 1984, pp. 479 y ss.; en concreto, pp. 518-520.
} 
sición gubernamental sobre las Fuerzas Armadas en orden a la misión que a éstas corresponde cumplir, de defensa del ordenamiento constitucional, de modo tal que cuando el Gobierno entienda que se ha producido o existe la amenaza de que se produzca una insurrección o acto de fuerza contra el ordenamiento constitucional, que no pueda resolverse por otros medios, vendrá obligado a proponer al Congreso de los Diputados la declaración del estado de sitio. Sólo así, con el necesario control parlamentario, podrá recurrirse a las Fuerzas Armadas para la defensa del ordenamiento constitucional.

\subsection{Otras misiones de las Fuerzas Armadas}

Las Fuerzas Armadas pueden cumplir otras misiones diferentes de aquellas que la Constitución específicamente contempla en su artículo 8.1, pues este precepto, como bien advierte LOPEZ RAMÓN ${ }^{161}$, no limita taxativamente el campo de actuación de las Fuerzas Armadas, bien que las misiones que en él se enumeran constituyan el ámbito competencial típico de los Ejércitos, es decir, las funciones que éstos realizan en cuanto tales, concretadas en intervenciones armadas.

I. El artículo 22.1 de la ley orgánica 6/1980 establece que: «Las Fuerzas Armadas, a requerimiento de la autoridad civil, podrán colaborar con ella en la forma que establezca la ley para casos de grave riesgo, catástrofe o calamidad u otra necesidad pública de naturaleza análoga.» Y en esa misma dirección, el artículo 193 de las Reales Ordenanzas para las Fuerzas Armadas dispone que en caso de catástrofe o calamidad pública el militar, salvo que tenga orden superior en contra, debe prestar su ayuda, poniendo todo su empeño en atenuar los daños y socorrer a los afectados.

La ley 2/1985, de 21 de enero, sobre Protección Civil -tras disponer en su artículo 2.1 que «las Fuerzas y Cuerpos de Seguridad, siempre que las circunstancias lo hicieren necesario, participarán en la protección civil», esto es, en la protección física de las personas y de los bienes, en situación de grave riesgo colectivo, calamidad pública o carástrofe extraordinaria, en la que la seguridad y la vida de las personas pueden peligrar y sucumbir masivamente-, establece en su artículo 2.2 que, asimismo, en tiempo de paz, cuando la gravedad de la situación de emergencia lo exija, las Fuerzas Armadas, a solicitud de las autoridades competentes, co-

161 Fernando LÓPEZ RAMÓN: La caracterización..., op. cit., p. 328. 
laborarán en la protección civil, dando cumplimiento a las misiones que se les asignen. La colaboración de las Fuerzas Armadas, que actuarán en todo caso encuadradas y dirigidas por sus mandos naturales, deberá solicitarse de la autoridad militar que corresponda (art. 2.3).

II. El segundo tipo de misiones, a diferencia de las anteriores, de proyección interna, se proyecta a un ámbito externo. Se trata de las misiones de mantenimiento de la paz. A ellas ya se referiría el artículo 9 de las Reales Ordenanzas para las Fuerzas Armadas, que dispone que cuando unidades militares españolas actúen en misiones de colaboración para mantener la paz y seguridad internacionales, se sentirán nobles instrumentos de la patria al servicio de tan elevados fines.

Las operaciones de mantenimiento de la paz, en su sentido clásico, han sido definidas por Naciones Unidas como aquellas operaciones que involucran a personal militar, bien que sin poderes de utilización de la fuerza de las armas para establecer esa misma paz que se pretende alcanzar; estas operaciones son organizadas por las Naciones Unidas para ayudar a mantener o restablecer la paz y seguridad internacionales en áreas de conflicto.

Las operaciones de mantenimiento de la paz no son acciones coercitivas que precisen una toma de decisión sobre la base del Capitulo VII de la carta de la ONU. No son operaciones de combate, pues tratan únicamente de controlar y garantizar el fin de las hostilidades y el restablecimiento de la paz. Las fuerzas de mantenimiento de la paz son órganos auxiliares de la Asamblea General de la ONU (art. 22 de la Carta) o del Consejo de Seguridad (art. 29). Gozan de un estatuto, privilegios e inmunidades, aunque los países participantes conservan la competencia disciplinaria y jurisdiccional penal exclusiva sobre el contingente de fuerzas que aportan a la operación.

Las fuerzas de mantenimiento de la paz no pueden tomar la iniciativa de utilizar la violencia, pero tienen el derecho a su propia defensa armada contra un ataque, comprendiendo las tentativas de desalojarles de las posiciones que ocupan por orden del mando.

\section{La sujeción de la organización militar a los principios constitucionales}

I. El párrafo segundo del artículo 8 determina que: "Una ley orgánica regulará las bases de la organización militar conforme a los principios de la presente Constitución.» 
Conviene recordar que el precepto fue objeto específico de varias enmiendas a lo largo del iter constituyente, de las que conviene recordar la enmienda n. ${ }^{\circ} 322$, del senador Sr. Sánchez Agesta, quien postularía una nueva redacción del párrafo del siguiente tenor: "Las leyes regularán las bases de la organización militar y los derechos y deberes específicos de sus miembros dentro de los principios de la presente Constitución", texto que entendía necesario el citado senador en base a la consideración de que de no existir esta cláusula general las hipotéticas especialidades del estatuto jurídico singular de los miembros de las Fuerzas Armadas no previstas de modo específico por la Constitución podrían denunciarse como inconstitucionales. Aunque, a nuestro entender, hubiera sido positiva esta referencia al estatuto jurídico-constitucional de los militares, no creemos, sin embargo, que la omisión de tal referencia conduzca a las consecuencias apuntadas por el citado senador ${ }^{162}$.

Esta previsión constitucional carece de antecedentes en nuestro Derecho histórico, aunque no así en el Derecho comparado. En efecto, el último párrafo del artículo 52 de la Constitución italiana de 1947 puede considerarse un antecedente directo del mismo. A su tenor: "L'ordinamento delle Forze armate si informa allo spirito democratico della Republica.» Esta disposición, al delimitar la esfera de discrecionalidad tanto del poder legislativo como del ejecutivo, pero, en lo que ahora interesa, especialmente del primero, ofrece un argumento sólido en el que apoyar la existencia de una reserva de ley para disciplinar el ordenamiento militar en su conjunto, tal y como razona LABRIOLA ${ }^{163}$, quien, a mayor abundamiento, considera que la exigencia constitucional de conformidad al espíritu democrático del ordenamiento de las Fuerzas Armadas no quedaría adecuadamente garantizada si no conllevase una reserva de ley en salvaguarda de la misma ${ }^{164}$.

162 También el senador Sr. Gambo Sánchez-Barcaiztegui se referiría en el Pleno del Senado (DSS, n. ${ }^{\circ}$ 59, 26 de septiembre de 1978, pp. 2943-2944) a una modificación al apartado segundo del art. 8 que, sin embargo, no aparece reflejada ni en su enmienda $n .{ }^{\circ} 172$, ni en su voto particular n. 54 al dictamen de la Comisión de Constitución del Senado. En su intervención ante el Pleno, el Sr. Gamboa aduciría que antes de establecer las bases de la organización militar era preciso sentar las de la defensa nacional, por su mayor generalidad. Se trataba, en definitiva, de encajar la "organización militar» en su marco natural, la "defensa militar", y ésta, a su vez, en el concepto más amplio de la "defensa nacional", apreciaciones todas ellas harto atinadas, como el desarrollo legislativo ulterior vendría a corroborar.

${ }_{163}$ Silvano LABRIOLA: "Difesa nazionale e sicurezza dello Stato nel diritto pubblico italiano", en Rivista Trimestrale di Diritto Pubblico, 1979, n. ${ }^{\circ} 4$, pp. 904 y ss.; en concreto, pp. 920 921.

164 LABriola ("Difesa nazionale...", op. cit., pp. 921-922) aduce tres razones en defensa de su tesis proclive a la exigencia implícita en el último párrafo del art. 52 de un principio de reserva de ley: $1 .^{2}$ ) la naturaleza legislativa de la ordenación permite acudir a una forma esencial de 
El párrafo segundo del artículo 8 viene a complementar al primero, por cuanto si éste, como ya señalamos, entre otras virtualidades, entraña la vinculación de las Fuerzas Armadas a unas específicas misiones enumeradas por el constituyente, y sólo a ellas, aquél completa la integración de las Fuerzas Armadas en la norma suprema al exigir que su organización se acomode a los principios constitucionales.

II. A modo de complemento del artículo 8.2 debe recordarse ahora, aunque sea de modo muy sucinto, que el artículo 149.1.4. ${ }^{\text {a }}$ atribuye al Estado la competencia exclusiva sobre la defensa y las Fuerzas Armadas, exclusividad que ha de ser entendida en su sentido más pleno, esto es, como competencia íntegra, que es aquella en la que se dispone de la totalidad de la materia por una única instancia, el Estado en este caso, al que se le atribuye el conjunto de todas las funciones públicas (ordenación y ejecución) sobre estas materias ${ }^{165}$.

Como bien dice CASADO BuRbano ${ }^{166}$, este monopolio estatal del máximo poder de coerción, representado por la posibilidad de disponer de las Fuerzas Armadas, tiene su fundamento en la propia concepción democrática de la soberanía nacional. Ciertamente, sólo se es soberano en la medida en que se es capaz de autodefenderse, y, por tanto, si en el pueblo reside esta soberanía, sólo a él corresponde, a través de la organización política que ha querido darse, el ejercicio libre de aquel máximo poder. Y esa organización política es la del Estado, con independencia ya del carácter complejo del mismo. De ahí que VeRGOTTINI haya podido afirmar rorundamente que sólo el Estado puede ser titular del poder de organización militar, ostentando un verdadero monopolio ${ }^{167}$.

Reflejo de este planteamiento puede ser la prohibición constitucional de organizaciones de carácter militar o paramilitar ${ }^{168}$. Y así, el párra-

garantía: el control de constitucionalidad (il controllo di legittimità) ejercitado por la "Corte Costituzionalem; 2.3 ) la reserva de ley viene a suponer un equilibrio entre los poderes al permitir al Parlamento regular la materia de modo abstracto y general, mientras que la inexistencia de tal reserva corresponde a los presupuestos institucionales de la prerrogativa regia, especialmente en su fase evolutiva más madura, y $3 .^{2}$ ) la reserva de ley implica la participación en el procedimiento legislativo de las fuerzas de la oposición parlamentaria, circunstancia que LABRIOLA, con toda razón, entiende esencial a la vista de los valores que el ordenamiento pretende tutelar a través de estos principios, que trascienden el ámbito del uindirizzo políticon de la mayoría.

165 En la misma dirección, Aurelio Guaita (en "Los derechos fundamentales de los militares", op. cit., p. 2570) cree que esta exclusividad ha de ser entendida en su acepción más rigurosa, exacta y amplia.

166 Pablo Casado Burbano: Iniciación al Derecho constitucional militar, op. cit., p. 51.

167. Giuseppe DE VERGOTTINI: Indirizzo politico della difesa e sistema costituzionale, Giuffrè, Milano, 1971, p. 131. Pablo CaSAdo BuRbano: Iniciación, op. cit., pp. 51-52.

168 Pablo Casado Burbano: Iniciación..., op. cit., pp. 51-52. 
fo segundo del artículo 18 de la Constitución italiana prescribe: "Sono proibite le associazioni segrete e quelle che perseguono, anche indirettamente, scopi politici mediante organizzazioni de carattere militare." Y el artículo 22.5 de nuestra "Lex superior" prevé: «Se prohíben las asociaciones secretas y las de carácter paramilitar.»

III. La reserva de ley orgánica, a juicio de SERRANo AlberCA ${ }^{169}$, ha de entenderse en el sentido de que las Fuerzas Armadas son consideradas como una de las instituciones básicas de la Constitución. Sin desechar esta interpretación, creemos que el constituyente, con tal reserva, buscó posibilitar el más amplio consenso parlamentario a la hora de aprobar la norma legal que aquí se contempla.

La primera cuestión interpretativa que suscita el artículo 8.2 es la de desbrozar lo que ha de entenderse por «bases» de la organización militar.

La ponencia constitucional, al rechazar la enmienda n. ${ }^{\circ} 463$, del Grupo Parlamentario Mixto ${ }^{170}$, entendía que la ley debe garantizar la organización básica de las Fuerzas Armadas, cuyo desarrollo articulado debería atenerse al contenido de la ley de bases ${ }^{171}$. Es decir, con claridad meridiana, la ponencia se inclinaba por entender la noción de «bases» en el sentido de una ley de bases, esto es, una ley que acogiera un conjunto de principios abstractos que la legislación de desarrollo procedería a desarrollar. Sin embargo, como la doctrina puso de relieve ${ }^{172}$ y la realidad legislativa ha corroborado, no es ése el sentido que ha de darse al concepto de "bases». Es decir, esta referencia a las "bases" no tiene nada que ver con la delegación legislativa, ni puede identificarse con las leyes mar$\mathrm{co}$, sino que ha de entenderse como noción material y, en consecuencia, las bases de la organización militar son los criterios generales, fundamentales, por los que ha de regirse la organización castrense. Como es lógico, el mayor o menor grado de concreción de estos criterios básicos ha de depender de los distintos aspectos organizativos.

La ley orgánica exigida por el artículo 8.2 es la ley orgánica 6/1980, a la que ya nos hemos referido en reiteradas ocasiones. Por ella se regulan los criterios básicos de la defensa nacional y la organización militar. La

\footnotetext{
16.) José Manuel Serrano Alberca: "Comentario al artículo 8.2", en Fernando Garrido Falla (dir.), Comentarios a la Constitución, op. cit., pp. 123 y ss.; en concreto, p. 124.

170 La enmienda, en relación al apartado segundo de este artículo, propugnaba la siguiente redacción: «Una ley regulará la organización militar con arreglo a los principios de la Constitución."

BOC, n. ${ }^{\circ} 82,17$ de abril de 1978 , p. 1527.

En tal sentido, entre otros, José Manuel Serrano Alberca: "Comentario al artículo 8.2", op. cit., p. 125. Asimismo, Fernando LOPEZ RAMON: La caracterización juridica..., op. cit., p. 347 , nota 56 .
} 
norma en cuestión, de 1 de julio de 1980, sería modificada por la ley orgánica $1 / 1984$, de 5 de enero. La ley desborda en su contenido el estrictamente circunscrito a la organización militar, para incluir un conjunto de previsiones referentes a la organización de la defensa nacional, lo que se explica por el hecho de que carecería de sentido dar rango orgánico a la organización castrense y excluir de tal rango la ordenación global de la defensa que, como dice el artículo 2 de la propia ley, afecta a todas las energías y fuerzas morales y materiales de la nación.

LÓPEZ RAMÓN ${ }^{173}$, al hilo de la jurisprudencia del Tribunal Constitucional sobre la reserva de ley orgánica ${ }^{174}$, ha considerado como «materias conexas» a la materia estrictamente reservada a ley orgánica los preceptos relativos a la organización general de la defensa nacional, no cabiendo, a su juicio, extender a la regulación de esas "materias conexas" la reserva de ley orgánica.

No compartimos la precedente interpretación. Es evidente, como ya advertimos con anterioridad, que el concepto de "defensa nacional" desborda la organización y acción de los Ejércitos, pero las Fuerzas Armadas son el elemento central de la defensa nacional, por lo que su organización, aunque en íntima vinculación con la defensa militar, no puede desvincularse del concepto más amplio, más global, de la defensa nacional. En suma, la organización castrense ha de encajarse en la defensa militar y ésta, a su vez, en la defensa nacional, reflexión que nos conduce a entender que la ordenación normativa de la organización militar presupone la regulación de la defensa nacional, conceptos que están tan imbricados entre sí que no pueden ser separados, razón por la cual no creemos que pueda hablarse de "materia conexa» al aludir a la defensa nacional, respecto de la específica reserva que el artículo 8.2 hace en relación a la organización militar.

IV. El artículo 8.2 exige la regulación de los criterios básicos de la organización militar de conformidad a «los principios de la presente Cons-

\footnotetext{
$173 \quad$ Ibidem, p. 348.

174 El Tribunal Constitucional, ya desde sus primeras sentencias, consideró que si es cierto que existen materias reservadas a leyes orgánicas (art. 8.1 CE), también lo es que las leyes orgánicas están reservadas a estas materias y que, por tanto, sería disconforme con la Constitución la ley orgánica que invadiera materias reservadas a la ley ordinaria (STC 5/1981, de 13 de febrero, fund. jur. 21, A/). Sin embargo, el Tribunal ha admitido que la ley orgánica puede contener preceptos no orgánicos relativos a materias conexas. Para ello es preciso, en primer término, que el núcleo de la ley afecte a materias reservadas a la ley orgánica, y, en segundo término, la ley orgánica sólo puede incluir preceptos que excedan del ámbito estricto de la reserva cuando su contenido desarrolle el núcleo orgánico y siempre que constituyan un complemento necesario para su mejor inteligencia (STC 76/1983, de 5 de agosto, fund. jur. $51, \mathrm{~d} /$ ).
} 
titución». Esta exigencia nos recuerda aquella otra, a la que ya aludimos, del artículo 52 de la Constitución italiana, que exige que el ordenamiento de las Fuerzas Armadas italianas se inspire «en el espíritu democrático de la República». Como bien señalara Vittorio BACHELET ${ }^{175}$, informar el espíritu democrático de la República no significa trasplantar el espíritu democrático a las Fuerzas Armadas, sino afirmar la plena sujeción del ordenamiento castrense al ordenamiento estatal democrático y recordar que el ordenamiento militar debe fundarse sobre la dignidad de la persona humana y sobre el pleno respeto de los derechos garantizados por la Constitución.

Entre nosotros, las interpretaciones doctrinales que se han formulado de esta exigencia del artículo 8.2 han sido dispares. Y así, LuCAS VERDU ${ }^{176}$ consideraría que los principios a que aludía el citado precepto eran no sólo la libertad, la igualdad, el respeto del pluralismo político y demás principios expresados en el Título I, sino también los principios explícitos e implícitos contenidos en todo el texto constitucional, como, por ejemplo, la dignidad de la persona humana y los derechos inviolables de la misma. LÓPEZ GARRIDO ${ }^{177}$, siguiendo a VeRGOTTINI, cree que el mandato del artículo 8.2 indica el propósito de garantizar una completa permeabilidad entre el ordenamiento del Estado y el ordenamiento militar, tradicionalmente separado, eliminando las reservas que pueda haber entre poder ejecutivo y vértice militar. SERRANo ALBERCA, por su parte, agrupa aquellos principios en tres grandes grupos ${ }^{178}: 1$ ) los principios y valores aplicables con carácter general que estén reconocidos a lo largo de todo el texto constitucional, pero muy especialmente en el Título Preliminar y en el Título primero; 2) los principios propios de la Administración reconocidos en los artículos 103 a 106 de la Constitución, y 3) los principios especialmente aplicables a las Fuerzas Armadas, esto es, la subordinación y obediencia de las Fuerzas Armadas al Gobierno, el mando supremo de las mismas por el jefe del Estado, el apartidismo de las Fuerzas Armadas y la especialidad de la jurisdicción militar. BLANCO VALDÉS ${ }^{179}$ considera que el principio fundamental, auténtica clave de

175 Cit. por Francisco JiMÉNEZ y JIMÉNEZ: Introducción al Derecho penal militar, Civitas, Madrid, 1987, p. 29.

176 Pablo LuCAS VERDÚ: “El Título I del anteproyecto constitucional» (La fórmula política de la Constitución), en el colectivo Estudios sobre el proyecto de Constitución, Centro de Estudios Constitucionales, Madrid, 1978, pp. 9 y ss.; en concreto, p. 23.

177 Diego López Garrido: "La posición constitucional de las Fuerzas Armadas", op. cit., pp. 963-964.

178 José Manuel Serrano AlberCa: “Comentario al artículo 8.2», op. cit., pp. 125-129.

179 Roberto BLANCO VALDES: La ordenación..., op. cit., pp. 82-88. 
arco de toda la labor de desarrollo legislativo, es el de subordinación de las Fuerzas Armadas a los órganos fundamentales del Estado. Finalmente, LOPEZ RAMON ${ }^{180}$ cree que el artículo 8.2 remite a una organización de las Fuerzas Armadas conforme a los principios administrativos.

A nuestro modo de ver, el encuadramiento de las bases de la organización militar $y$, en el sentido amplio con que entendemos ese concepto, de la defensa nacional, en el marco de los principios constitucionales tiene como primera exigencia el acomodo de la ordenación de la defensa nacional y de la organización militar a los específicos principios constitucionales que nuestra norma suprema contempla en relación a las Fuerzas Armadas:

- En primer término, la sujeción de las Fuerzas Armadas al poder civil, inequívocamente reflejada en el artículo 97 de la Constitución, cuando atribuye al Gobierno la dirección de la Administración militar y de la defensa del Estado.

- En segundo lugar, la atribución del mando supremo de las Fuerzas Armadas al rey, con el significado que a ello ha de darse en una monarquía parlamentaria, forma política de nuestro Estado.

- En tercer término, la delimitación del ámbito competencial de la jurisdicción militar al «ámbito estrictamente castrense» como regla general impuesta por el artículo 117.5 de la Constitución, al igual que la ordenación de su ejercicio de conformidad con los propios principios constitucionales.

- En cuarto lugar, la configuración de un estatuto jurídico peculiar para los miembros de las Fuerzas Armadas, del que constituyen manifestaciones puntuales las determinaciones de los artículos 28.1, 29.2 y 70.1, e/, de la Constitución. Este estatuto encuentra su última "ratio", como ya tuvimos oportunidad de señalar, en el mantenimiento de los que pueden ser considerados principios nucleares de la organización castrense: la unidad, la jerarquía y la disciplina.

- En quinto término, la configuración de la defensa de España como un derecho y deber de todos los españoles, que se ha de modular en los términos del artículo 30.2 de la norma suprema.

- Finalmente, la atribución al Estado de la competencia exclusiva en materia de defensa y Fuerzas Armadas, lo que significa, de un lado, que a las Cortes Generales les corresponde la potestad de ordenación de estos ámbitos materiales y al Gobierno la potestad de ejecución; y de otro,

ik1 Fernando LOPEZ RAMON: La caracterización juridica..., op. cit., pp. 332-352. 
que el principio de descentralización no es de aplicación a estas materias.

Una segunda exigencia que dimanaría del artículo 8.2 sería lógicamente la del acomodo de la defensa nacional y de la organización castrense a los valores y principios constitucionales que nuestra norma uprema proclama a lo largo y ancho de su articulado, pero, muy específicamente, en los Títulos Preliminar y primero.

Finalmente, a los órganos de la Administración militar, en cuanto Administración pública que son, les son de aplicación los principios que enuncia el artículo 103.1 y 2 de la Constitución, con la ya referida salvedad del principio de descentralización. Y de la misma forma, el acceso a la profesión militar ha de estar regido por las previsiones del artículo 103.3, siendo asimismo de especial importancia que la enseñanza militar propicie una formación de los miembros de las Fuerzas Armadas acorde con los principios que la norma suprema establece.

En este último plano principal, hay que señalar que la ley orgánica 6/ 1980 determina que la organización de las Fuerzas Armadas se inspirará en criterios de coordinación y eficacia conjunta de los tres Ejércitos que las integran, a cuyo efecto se tenderá a unificar todos los servicios cuya misión no sea exclusiva de un solo Ejército para permitir el funcionamiento conjunto con criterios de eficacia y economía de medios. A su vez, los tres Ejércitos se han de estructurar orgánica y funcionalmente con vistas al cumplimiento conjunto de las misiones constitucionalmente encomendadas a las Fuerzas Armadas.

La enseñanza militar, que el artículo 27.1 de la citada ley considera parte fundamental de la preparación del militar en todos sus niveles, ha de tener como misión fundamental el dotar a las nuevas promociones de oficiales y suboficiales de la más alta preparación en orden al cumplimiento de los fines asignados por la Constitución a las Fuerzas Armadas.

Digamos por último que la citada ley (en su art. 26.1) remite a las Reales Ordenanzas, regla moral de la institución militar, la determinación de las obligaciones, normas de conducta, deberes y derechos específicos de las Fuerzas Armadas, así como del régimen de vida y disciplina de las unidades. 


\section{Bibliografía}

BaLlbé, Manuel

1983 Orden público y militarismo en la España constitucional(1812-1983), Alianza Universidad, Madrid.

BARCELONA LLOP, Javier

1986 «La organización militar: apuntes jurídico-constitucionales sobre una realidad estatal", en Revista de Administración Pública, n. ${ }^{\circ} 110$, mayoagosto, pp. 55 y ss.

BLANCO VALDÉS, Roberto

1988 La ordenación constitucional de la defensa, Tecnos, Madrid.

Cano Hevia, Juan

1984 "Fuerzas Armadas", en J. J .González Encinar (dir. ), Diccionario del sistema político español, Akal Editor, Madrid, pp. 349 y ss.

Casado Burbano, Pablo

1986 Iniciación al Derecho constitucional militar, Editorial Revista de Derecho Privado, Madrid.

1978 "Las Fuerzas Armadas en la nueva Constitución española", en Revista Española de Derecho Militar, n. ${ }^{\circ} 36$, julio-diciembre, pp. 7 y ss.

DE OTTO, Ignacio

1988 "El mando supremo de las Fuerzas Armadas", en Revista Española de Derecho Constitucional, n. ${ }^{\circ} 23$, mayo-agosto, pp. 11 y ss.

Díez Alegría, Manuel

1979 "La defensa en el proceso constitucional", en Anales de la Real Academia de Ciencias Morales y Políticas, n. 56 (curso 1978-1979), pp. 159 y ss.

1973 Ejército y sociedad, Alianza Editorial , 2. ${ }^{2}$ ed., Madrid.

Dominguez-Berrueta de Juan, Miguel (y otros)

1988 El control jurídico-constitucional de la transición militar (Relevancia y conexiones constitucionales del art. 8.1 CE), en el colectivo Jornadas de estudio sobre el Título Preliminar de la Constitución, vol. IV, Ministerio de Justicia, Madrid, pp. 2953 y ss.

Dugue Villanueva, Juan Carlos

1988 "El mando supremo de las Fuerzas Armadas", en el colectivo Jornadas de estudio sobre el Título Preliminar de la Constitución, op. cit., vol. IV, pp. 2529 y ss. 
Elorriaga Fernández, Gabriel

1988 "El artículo 8 de la Constitución y la institución nacional de las Fuerzas Armadas", en el colectivo Jornadas de estudio sobre el Título Preliminar de la Constitución, op. cit., vol. IV, pp. 2545 y ss.

FERNÁNDEZ EsPeso, Carlos

1985 "Defensa nacional y seguridad nacional", en el colectivo Libertades públicas y Fuerzas Armadas, Ministerio de Educación y Ciencia e Instituto de Derechos Humanos, Madrid, pp. 797 y ss.

Fernández-Fontecha Torres, Manuel, y Pérez de Armiñán, Alfredo

1987 La monarquía y la Constitución, Editorial Civitas, Madrid.

Garcia Arias, Luis

1967 "Las Fuerzas Armadas en la ley orgánica del Estado", en Revista de Estudios Politicos, n. ${ }^{\circ}$ 152, marzo-abril, pp. 137 y ss.

Gonzalez Vallejo, Roberto

1992 «La Defensa nacional, las Fuerzas Armadas y la Constitución espanola de 1978", en el colectivo Posición constitucional de las Fuerzas Armadas en Iberoamérica y en España, Tecnos-Universidad Hispanoamericana Santa María de la Rábida-Universidad de Sevilla, Madrid, pp. 123 y ss.

Herrero de Miñón, Miguel

1980 "El rey y las Fuerzas Armadas", en Revista del Departamento de Derecho Político, n. 7 , otoño, pp. 39 y ss.

Labriola, Silvano

1979 «Difesa nazionale e sicurezza dell Stato nel diritto pubblico italiano", en Rivista Trimestrale di Diritto Pubblico, n. ${ }^{\circ}$, pp. 904 y ss.

LAFUENTE BALle, José M. ${ }^{2}$

1987 El rey y las Fuerzas Armadas en la Constitución, Editorial Revista de Derecho Privado, Madrid.

LÓpez Aguil.ar, Juan Fernando

1995 "Defensa, interés nacional y seguridad colectiva" (Acotaciones conceptuales desde el ordenamiento constitucional español), en el colectivo Constitución y Derecho público (Estudios en homenaje a Santiago Varela), Tirat lo Blanch, Valencia, pp. 241 y ss.

LÓPEz GaRrido, Diego

1983 "La posición constitucional de las Fuerzas Armadas", en Revista de Administración Pública, n. ${ }^{\text {os }}$ 100-102, vol. II, enero-diciembre, pp. 949 y ss. 
López Ramón, Fernando

1987 La caracterización juridica de las Fuerzas Armadas, Centro de Estudios Constitucionales, Madrid.

Martínez Lopez-Muñiz, José Luis

1988 "Fuerzas Armadas y Administración pública», en el colectivo Jornadas de estudio sobre el Título Preliminar de la Constitución, op. cit., vol. IV, pp. 2699 y ss.

Oehling Ruiz, Hermann

1967 La función política del Ejército, Instituto de Estudios Políticos, Madrid.

Pérez Escolar, Rafael

1981 Constitución y Fuerzas Armadas, Asociación Independiente, Madrid.

Porras Nadales, Antonio

1983 "Ordenamiento de la defensa, poder militar y régimen constitucional en España", en Revista de Estudios Políticos, n. 35 (nueva época), sepriembre-octubre, pp. 183 y ss.

SÁnChez Agesta, Luis

1982 "La Constitución y las Fuerzas Armadas", en el colectivo Primeras Jornadas Fuerzas Armadas-Universidad, Centro Superior de Estudios de la Defensa Nacional, Madrid, pp. 147 y ss.

Serrano Alberca, José Manuel

1985 "Comentario al artículo 8 de la Constitución", en Fernando Garrido Falla (dir.), Comentarios a la Constitución, Civitas, $2 .^{a}$ ed., Madrid, pp. 116 y ss.

SuÁrez Pertierra, Gustavo

1988 "Regulación jurídico-constitucional de las Fuerzas Armadas", en el colectivo Jornadas de estudio sobre el Título Preliminar de la Constitución, op. cit., vol. IV, pp. 2359 y ss.

Trillo Figueroa y Martinez-Conde, Federico

1979 "Las Fuerzas Armadas en la Constitución espańola» (Esbozo de una construcción institucional), en Revista de Estudios Políticos, n. ${ }^{\circ} 12$ (nueva época), noviembre-diciembre, pp. 105 y ss.

VERGOTTINI, Giuseppe de

1971 Indirizzo Politico della difesa e sistema costituzionale, Guiffrè, Milano.

Villagra Blanco, Daniel

1980 "Ley orgánica por la que se regulan las bases de la defensa nacional y la organización militar", en Cuadernos de Documentación, n. 35, Secretaría General Técnica, Presidencia del Gobierno, Madrid. 